\title{
Comparative DFT+U and HSE Study of the Oxygen Evolution Electrocatalysis on Perovskite Oxides
}

Tripkovic, Vladimir; Hansen, Heine Anton; García Lastra, Juan Maria; Vegge, Tejs

\section{Published in:}

The Journal of Physical Chemistry Part C

Link to article, DOI:

10.1021/acs.jpcc.7b07660

Publication date:

2018

Document Version

Peer reviewed version

Link back to DTU Orbit

Citation (APA):

Tripkovic, V., Hansen, H. A., García Lastra, J. M., \& Vegge, T. (2018). Comparative DFT+U and HSE Study of the Oxygen Evolution Electrocatalysis on Perovskite Oxides. The Journal of Physical Chemistry Part C, 122(2), 1135-1147. https://doi.org/10.1021/acs.jpcc.7b07660

\section{General rights}

Copyright and moral rights for the publications made accessible in the public portal are retained by the authors and/or other copyright owners and it is a condition of accessing publications that users recognise and abide by the legal requirements associated with these rights.

- Users may download and print one copy of any publication from the public portal for the purpose of private study or research.

- You may not further distribute the material or use it for any profit-making activity or commercial gain

- You may freely distribute the URL identifying the publication in the public portal 


\title{
Comparative DFT $+U$ and HSE Study of the Oxygen Evolution Electrocatalysis on Perovskite Oxides
}

\author{
Vladimir Tripkovic*, Heine A. Hansen, Juan M. Garcia-Lastra, Tejs Vegge \\ ${ }^{1}$ Department of Energy Conversion and Storage, Technical University of Denmark, DK-2800 Kgs. \\ Lyngby, Denmark.
}

Abstract: The most common method for incorporating strong electron correlations is either to apply the Hubbard U correction on top of standard density functional theory calculations (DFT) or to use hybrid functionals. In this study, we elucidate the sensitivity of the Hubbard U correction in the $P B E+U$ functional and the amount of exact exchange, $\alpha$, in the hybrid HSE functional on the structural stability, catalytic activity and electronic conductivity of pure and doped perovskite oxides, $\mathrm{ABO}_{3}$, ( $\mathrm{A}=\mathrm{La}, \mathrm{Ca}, \mathrm{Sr}$ and $\mathrm{Ba}, \mathrm{B}=\mathrm{Cr}, \mathrm{Mn}, \mathrm{Fe}, \mathrm{Co}, \mathrm{Ni}$ and $\mathrm{Cu}$ ) for oxygen evolution electrocatalysis. We find a strong dependence of heat of formations and reaction overpotentials for a range of $U=0,3$ and $5 \mathrm{eV}$ and $\alpha=0,0.15,0.25,0.35$ values investigated in this study, which we attribute primarily to changes in the oxidation state of $B$ cations. If the valence of $B$ cations in the perovskite and reference oxide is the same, then the $U$ - and $\alpha$ dependence is very small. On the other hand, if the valences are different then heat of formations can change by as much as $1 \mathrm{eV}$. As the oxidation state of a surface metal ion depends on adsorbed intermediate and nature of the element, similar differences in energies appear in the calculated reaction overpotentials for oxygen evolution. The large $U$ and $\alpha$ dependence sets serious constraints on the use of DFT+U and HSE methods for assessing stabilities and catalytic activities of perovskite oxides. In addition, the large $\alpha$ dependence raises the question whether HSE calculations can improve sufficiently the accuracy of DFT $+U$ results for multi-step electrochemical reactions to justify the excess computational cost. Although we have investigated only one particular class of catalysts and one electrochemical reaction, the results of this study can expectedly be generalized to other strongly correlated systems in which the oxidation state of the surface changes during reaction. The influence of $U$ on the electronic conductivity is significant only in cases where it qualitatively changes the electronic structure, by e.g. opening the band-gap. From a combinatorial analysis on pure and doped oxides, we identify electronically conductive catalysts classified according to different electron conduction types: intrinsic conductivity $\left(\mathrm{Fe}^{4+}, \mathrm{Co}^{3+}\right.$ (intermediate spin, $\left.\mathrm{IS}\right)$ and $\mathrm{Ni}^{3+}$ ), electron polaron hopping (along $\mathrm{Mn}^{3+}{ }_{-} \mathrm{O}-\mathrm{Mn}^{4+}$ chains) and charge transport through holes in the valence band.

*corresponding author: vltr@,dtu.dk

\section{Introduction}

Perovskite oxides are earth-abundant, cheap ceramic materials with versatile application in industry. They can be used as ionic conductors in solid oxide fuel cells ${ }^{1-3}$, magnetoresistors $^{4,5}$, superconductors ${ }^{6,7}$, sensors ${ }^{8,9}$, electrocatalysts in metal-air batteries and fuel cells. ${ }^{10-12}$ Their versatility stems from flexible structures that can be easily manipulated 
by means of doping. In contrast, the structural flexibility is also a shortcoming as active compositions might decay during operation.

The oxygen evolution reaction (OER) is a bottleneck in direct solar and electrocatalytic water splitting cells and rechargeable aqueous metal-air batteries. Improving the costefficiency of these devices requires development of efficient, cheap and stable oxygen evolving catalysts. A good catalyst material should fulfil three basic conditions, namely: i) the composition and structure should be stable at the conditions of interest, which we set in the $\mathrm{U}=1.7-1.8 \mathrm{~V}$ range vs. the Reversible Hydrogen Electrode (RHE), ii) it should be able to conduct electrons from the active site, and iii) it should be sufficiently active to catalyze water oxidation to oxygen. A prerequisite for tuning the structure and composition for targeted applications is to establish causal relationships between the electronic structure and fundamental material properties. The electronic structure contains all necessary information about the material, similar to the DNA in living cells. The activity of perovskite oxides for oxygen evolution/reduction has been related in past to electronic structure properties, such as the filling of the $\mathrm{d}$ band, ${ }^{10,12}$ the position of the $\mathrm{p}$ band center, ${ }^{13,14}$ charge transfer energy, ${ }^{15}$ adsorption energy of reaction intermediates etc. ${ }^{16,17}$ In fact, 14 different parameters were found to control the oxygen evolution/reduction activity to a smaller or greater extent. ${ }^{18}$ Furthermore, the same study revealed that the interplay of different factors is so convoluted that it is essentially impossible to make a universal model that describes the behaviour of all studied systems. This is mainly due to strong correlation effects present in transition metal oxides that are often very intricate and hard to capture with state-of-the-art methods.

Most of the experimental results on the activity and stability of transition metal oxides are from thin film electrode studies. The focus in this work is on bulk architectures. Their advantage is that they can be used as is, i.e. without any complex mechanical or chemical processing. Bulk oxide electrodes often suffer from poor electronic conductivity, which is not the case for thin films due to presence of defects, axial strain, surface states and electric field. An example where the conductivity changes going from bulk to thin film catalysts is $\mathrm{LaMnO}_{3} \cdot \mathrm{LaMnO}_{3}$ is a bulk semiconductor, but becomes conducive to electron transport when applied as thin films or heterostructures. ${ }^{19-21}$

The study is carried out using Density Functional Theory (DFT) calculations. Here, we have selected a subset of perovskite oxides, $\mathrm{ABO}_{3}$, where $\mathrm{A}=\mathrm{La}, \mathrm{Ca}, \mathrm{Sr}$ or $\mathrm{Ba}$ and $\mathrm{B}=\mathrm{Cr}$, 
$\mathrm{Mn}, \mathrm{Fe}, \mathrm{Co}, \mathrm{Ni}$ or $\mathrm{Cu}$. The reason for selecting this particular subset is in a unique feature of first-row transition metals to accommodate a variety of oxidation states, thus offering nearoptimal binding energies for different reaction intermediates. The change in the oxidation state results in relatively low reaction overpotentials. In the perfect cubic perovskite crystal, A cation is sitting in a cage surrounded by 12 equidistant oxygen ions, while $\mathrm{B}$ cation is octahedrally coordinated to 6 oxygen ligands. The ideal cubic structure may be distorted depending on the size of the $\mathrm{A}$ and $\mathrm{B}$ cation. ${ }^{22}$

Following the previous findings, we do not attempt to describe all the selected oxides with a simple universal relationship, but instead, endeavour to disentangle and understand the complex interplay between the magnetic, electronic and geometric factors and elucidate their influence on the structural stability, catalytic activity and electronic conductivity. A special emphasis is devoted to evaluating and comparing the results using state-of-the-art computational methods, such as DFT+U and hybrid calculations.

The paper is structured in the following way: first, we tabulate and discuss the main electronic, geometric and magnetic properties of selected pure oxides. Afterwards, we evaluate structural stabilities through the analysis of heats of formation, catalytic activities through computed reaction overpotentials and the electronic conductivities through the analysis of the electronic density of states (DOS). On the basis of the presented results we discuss how reliably DFT+U and hybrid calculations can be used to model perovskite oxides and other strongly correlated systems in general.

\section{Method}

For total energy calculations we used the planewave Vienna ab initio Simulation Package 23 (VASP) code (version 5.3.2) with the projector augmented-wave (PAW) pseudopotentials and the $\mathrm{PBE}^{24}$ exchange-correlation functional. We apply default pseudopotentials, except for $\mathrm{Ca}, \mathrm{Sr}$ and $\mathrm{Ba}$, where we use $\mathrm{Ca} \_\mathrm{pv}, \mathrm{Sr} \_s v$ and $\mathrm{Ba} \_$sv. We set the energy cutoff to 500 $\mathrm{eV}$, which is $100 \mathrm{eV}$ higher than the default cutoff for the most demanding, among the considered elements, O PAW pseudopotential. We used the 3x3x2 Monkhorst Pack k-point mesh for bulk hexagonal (6 formula units) and orthorhombic (4 formula units) unit cells, $6 \times 6 \times 6$ for cubic ( 1 formula unit) and $4 \times 4 \times 4$ for hexagonal ( 2 formula units) unit cell with face-shared octahedra. All calculations are performed as spin-polarized. We used the on-site Hubbard $U$ correction, where $U$ is defined as $U_{\text {eff, }}$ i.e. a difference between the screened 
Coulomb and exchange parameter, $\mathrm{U}_{\text {eff }}=\mathrm{U}-\mathrm{J} .{ }^{25}$ We used three representative $\mathrm{U}$ values (U $=0,3$ and $5 \mathrm{eV}$ ) to investigate the sensitivity of the structural stability, catalytic activity and electronic conductivity on U-parameter. We compared the results against the hybrid HeydScuseria-Ernzerhof (HSE) calculations performed on top of pre-converged DFT+U results by setting PRECFOCK=Fast and TIME $=0.4 .^{26}$ To reduce the computational cost the bulk lattice constants in the HSE calculations are kept fixed to the DFT+U $=5 \mathrm{eV}$ values. As was recently shown, the amount of exact exchange, i.e. the mixing parameter $(\alpha)$ in the HSE functional decreases along the transition metal series, suggesting that $\alpha$ needs to be fitted to experimental values similarly to $U$ in DFT+U calculations. ${ }^{27}$ To test the sensitivity of the HSE results on $\alpha$, we used discrete $\alpha=0,0.15,0.25$ and 0.35 values. We set the range separation parameter to $0.25 \AA^{-1}$, which is in-between those for HSE03 and HSE06 XC functionals. In Table 1, we show on the example of the $\mathrm{OH}$ binding energy, which often makes the potential determining step, that the influence of the range separation parameter is much smaller in comparison to that of $\alpha$ (vide supra).

Table 1 The binding energy of $\mathrm{OH}$ in units of electron volts as a function of the range separation parameter.

\begin{tabular}{|lccc|}
\hline & $\mathrm{LaCrO}_{3}$ & $\mathrm{LaMnO}_{3}$ & $\mathrm{LaFeO}_{3}$ \\
$\mathrm{r}=0 \AA^{-1}$ & 1.10 & 1.39 & 1.70 \\
$\mathrm{r}=0.15 \AA^{-1}$ & 1.11 & 1.40 & 1.71 \\
$\mathrm{r}=0.20 \AA^{-1}$ & 1.09 & 1.53 & 1.77 \\
$\mathrm{r}=0.25 \AA^{-1}$ & 0.99 & 1.46 & 1.70 \\
$\mathrm{r}=0.30 \AA^{-1}$ & 1.07 & 1.50 & 1.64 \\
\hline
\end{tabular}

To model oxide surfaces we use the most stable (001) perovskite facet. We model surfaces of $\mathrm{LaNiO}_{3}$ and $\mathrm{LaCoO}_{3}$ having the same orthorhombic crystal structure as other members of the La perovskite family following approach in Ref. ${ }^{28}$. We use a rather thin slab of 4 layers ( $2 \mathrm{AO}$ and $2 \mathrm{BO}_{2}$ layers), with $2 \mathrm{~B}$ cation sites in the surface unit cell. The binding free energy of $\mathrm{OH}$ on $\mathrm{LaMnO}_{3} / \mathrm{LaFeO}_{3}$ increases from 1.61/1.80 to 1.67/1.92 eV with the increase of the slab size from 4 to 6 layers. The variation in the adsorption energy with the slab thickness is much smaller in comparison to changes at different $\mathrm{U}$ values (vide supra). We keep the bottom layer fixed to represent the bulk crystal, while we relax 
remaining atoms until the forces are below $0.03 \mathrm{eV} / \AA$ in DFT $+\mathrm{U}$ calculations. For HSE calculations we assume convergence if the total energy changes by less than $0.01 \mathrm{eV}$ in the last 5 steps.

The calculated magnetic moment sometimes departs from the value expected from crystal field splitting and spin ordering, for instance, the magnetic moment of $\mathrm{Fe}^{3+}$ in $\mathrm{LaFeO}_{3}$ at $\mathrm{U}=5 \mathrm{eV}$ is 4.26 and not $5.0 \mu_{\mathrm{B}}$. Furthermore, there are cases in which the nominal and real oxidation states are not the same, e.g. $\mathrm{Co}$ in $\mathrm{CaCoO}_{3}$ or $\mathrm{SrCoO}_{3}$ is closer to $\mathrm{Co}^{+3}$ than $\mathrm{Co}^{+4}$.

As a measure of the electrochemical stability at the given conditions, we use the heat of formation calculated against individual oxide phases stable in the pertinent potential window. For the perovskite oxides investigated in this work $\mathrm{Cr}_{2} \mathrm{O}_{3}, \mathrm{Fe}_{2} \mathrm{O}_{3}, \mathrm{MnO}_{2}, \mathrm{CoO}_{2}$, $\mathrm{NiO}_{2}$, and $\mathrm{CuO}$ are used as references for calculating heats of formation. It is worth noting that $\mathrm{Cr}$ and $\mathrm{Fe}$ are not stable as solid oxides under OER conditions, but as dissolved $\mathrm{CrO}_{4}{ }^{2-}$ and $\mathrm{FeO}_{4}{ }^{2-}$ ions. ${ }^{29}$ The potentials at which $\mathrm{Fe}$ and $\mathrm{Cr}$ start to dissolve are found to be approximately $0.7 \mathrm{~V}$ at $\mathrm{pH}=7 .{ }^{29}$ At $\mathrm{U}=1.7 \mathrm{~V}$ vs. RHE relevant for oxygen evolution, the electrochemical stability is considerably overestimated because it is calculated against the oxide phases, instead of the more stable dissolved species in solution. Notable, Fe might not fully dissolve, but instead form an inert layer that will passivate the surface. ${ }^{30}$ The reason why we use oxide references is because $\mathrm{LaFeO}_{3}$ and $\mathrm{LaCrO}_{3}$ can be employed in high temperature electrolysis/fuel cells, where there is no metal ion dissolution.

The expression for calculating heats of formation depends on the valence of $\mathrm{A}$ and $\mathrm{B}$ cations. If $\mathrm{A}$ is a trivalent ion, formation energy is calculated as:

$$
\begin{aligned}
& \Delta \mathrm{G}_{\mathrm{f} / \mathrm{o}}=\mathrm{G}\left(\mathrm{LaBO}_{3}\right)-\frac{1}{2} \mathrm{G}\left(\mathrm{La}_{2} \mathrm{O}_{3}\right)-\frac{1}{2} \mathrm{G}(\mathrm{BO})-\frac{1}{2} \mathrm{G}\left(\mathrm{O}_{2}\right), \\
& \Delta \mathrm{G}_{\mathrm{f} / \mathrm{o}}=\mathrm{G}\left(\mathrm{LaBO}_{3}\right)-\frac{1}{2} \mathrm{G}\left(\mathrm{La}_{2} \mathrm{O}_{3}\right)-\frac{1}{2} \mathrm{G}\left(\mathrm{B}_{2} \mathrm{O}_{3}\right) \quad \text { and } \\
& \Delta \mathrm{G}_{\mathrm{f} / \mathrm{o}}=\mathrm{G}\left(\mathrm{LaBO}_{3}\right)-\frac{1}{2} \mathrm{G}\left(\mathrm{La}_{2} \mathrm{O}_{3}\right)-\mathrm{G}\left(\mathrm{BO}_{2}\right)+\frac{1}{4} G\left(\mathrm{O}_{2}\right),
\end{aligned}
$$

for di-( $\mathrm{Cu})$, tri-( $\mathrm{Cr}$ and $\mathrm{Fe})$ and tetravalent ( $\mathrm{Mn}, \mathrm{Co}$ and $\mathrm{Ni}) \mathrm{B}$ cations. Symbol ' $\mathrm{f} / \mathrm{O}$ ' in the subscript designates that formation energy is calculated from relevant oxide phases and not from constituent elements $\mathrm{A}, \mathrm{B}$ and $\mathrm{O}_{2}$, which is assumed under conventional definition of formation energy. If $\mathrm{A}$ is a divalent $(\mathrm{Ca}, \mathrm{Sr}$ or $\mathrm{Ba})$ ion, formation energy reads: 
$\Delta \mathrm{G}_{\mathrm{f} / \mathrm{o}}=\mathrm{G}\left(\mathrm{ABO}_{3}\right)-\frac{1}{2} \mathrm{G}\left(\mathrm{B}_{2} \mathrm{O}_{3}\right)-\mathrm{G}(\mathrm{AO})-\frac{1}{4} \mathrm{G}\left(\mathrm{O}_{2}\right)$ and

$\Delta \mathrm{G}_{\mathrm{f} / \mathrm{o}}=\mathrm{G}\left(\mathrm{ABO}_{3}\right)-\mathrm{G}\left(\mathrm{BO}_{2}\right)-\mathrm{G}(\mathrm{AO})$

for tri- and tetravalent B cations.

We make a conjecture for the doped catalysts that the crystal structure does not change within the investigated dopant concentration ( $x<0.25)$; i.e. $\mathrm{LaB}_{1-\mathrm{x}} \mathrm{B}_{\mathrm{x}} \mathrm{O}_{3}$, where $\mathrm{B}$ ' is the dopant atom, has the same crystal structure as its terminal member $\mathrm{LaBO}_{3}$. The free energy is computed from the energy calculated with DFT extrapolated to $\mathrm{T}=0 \mathrm{~K}$. We take the entropy of oxides to be zero and include the entropy term only in $\mathrm{G}\left(\mathrm{O}_{2}\right)$. DFT notoriously overestimates the oxygen binding energy. ${ }^{31}$ To get accurate heats of formations in eqs. (1), (3) and (4) that involve oxygen, the energy of oxygen is corrected using the $1 / 2 \mathrm{O}_{2}+\mathrm{H}_{2}=$ $\mathrm{H}_{2} \mathrm{O}$ reaction. The difference in the reaction free energy between the calculated and experimental value is $0.37 \mathrm{eV}$ per oxygen for $\mathrm{PBE}$ and $0.16,0.11$ and $0.06 \mathrm{eV}$ for $\alpha=0.15$, 0.25 and 0.35 , respectively in HSE calculations. For calculating adsorption free energies and reaction overpotentials we used the approach outlined in refs. 32 and 33.

\section{Results and Discussion}

\subsection{Pristine oxides}

We start the analysis by discussing geometric (crystal structure, Goldschmidt tolerance factor), magnetic (types of magnetism and spin ordering) and electronic (electron conduction type, $e_{g}$ electron count, the $U$ correction) properties of the selected oxides. As we shall see, these properties are not independent but coupled. Table 1 contains a summary of data computed in this work and taken from literature regarding the most important properties of the selected perovskite oxides. For each column, we explain the data in detail and discuss their implications.

The conduction type is denoted in column 2 (in the case of a semiconductor, the value for the band-gap is given in brackets). There are various approaches to determine the size of the band-gap from optical absorption spectra, which is the main reason why values in the literature differ by approximately $10-20 \% .{ }^{34} \mathrm{We}$ find that the size of the band-gap reduces in the first-row transition metal series because the large charge on the nucleus shifts the metal $3 \mathrm{~d}$ orbitals down. The downshift in turn enhances the hybridization of the $\mathrm{O} 2 p$ and 
metal $3 d$ states resulting in broadening of the band-width and a concomitant decrease of the band gap. ${ }^{35}$ Noticeably, $\mathrm{Mn}$ is the only point that sticks out from the general band-width trend.

The third column shows the preferred crystal structure. We discriminate among five different crystal structures: cubic, tetragonal, orthorhombic and two types of hexagonal, with corner- and face-shared octahedra (cf. Figure 1). The tetragonal and orthorhombic cells are derived from the cubic cell by applying axial strain in one or two crystal directions, respectively. Face-shared octahedra form one dimensional chains as in e.g. $\mathrm{BaCoO}_{3}{ }^{36}$

a)

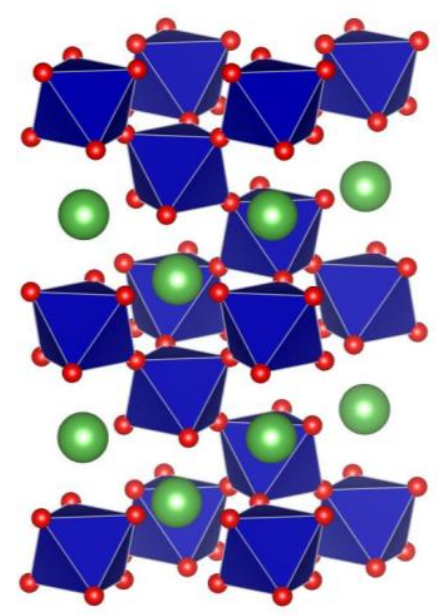

b)

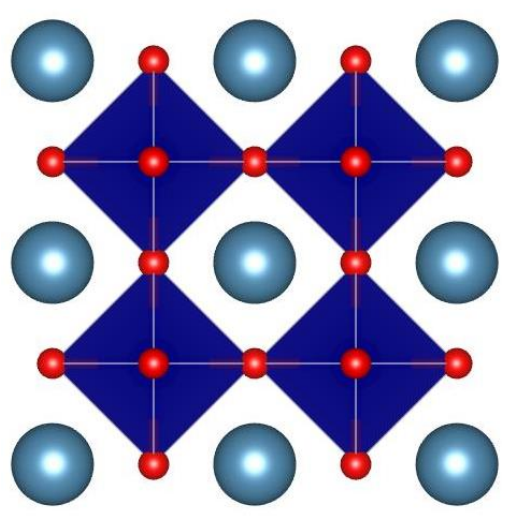

c)

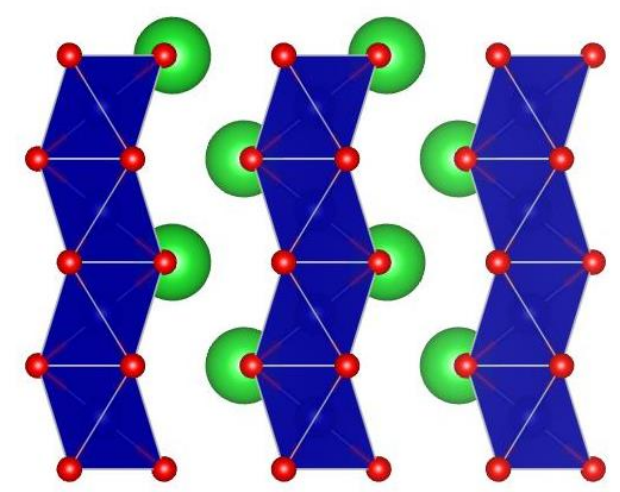

Figure 1 Side views of three respective crystal structures a) hexagonal $\mathrm{LaCoO}_{3}$ with tilted cornershared octahedra b) cubic $\mathrm{CaCoO}_{3}$ with straight corner-shared octahedra and c) hexagonal $\mathrm{BaCoO}$ with face-shared octahedra. Opaque octahedra show octahedrally coordinated B cations.

Another important geometric parameter not listed in Table 2 is the metal-oxygen-metal (M$\mathrm{O}-\mathrm{M})$ bond angle. In cubic structures, the angle is $180^{\circ}$ and for all the other structures it is < $180^{\circ}$. The angle depends on the degree of tilting of the $\mathrm{BO}_{6}$ octahedrons and arises as a result of axial stress produced by the incommensurate A and B cation sizes and/or JahnTeller (JT) distortions. A good example where this effect comes into play is a class of lanthanide nickelates. ${ }^{37}$ Column 5 contains values for the Goldschmidt tolerance factor. For $t \approx 1$, the structure is cubic, if $t<1$, the oxide crystallizes either in the tetragonal, orthorhombic or corner-shared hexagonal unit cell, and if $t>1$, the structure is often hexagonal with face-shared octahedra. ${ }^{38}$ Many structures with $\mathrm{Ba}$ at the A site are with faceshared octahedra (cf. Figure 1), due to a large $\mathrm{Ba}^{2+}$ cation size. According to crystal field theory, $d$ orbitals of an octahedrally coordinated ion are split into a doublet $\left(e_{g}\right)$ and a triplet 
$\left(t_{2 g}\right)$. The crystal field splitting increases with the ion's oxidation state and ionic radius from left to right in the transition metal series. For this reason, $\mathrm{Fe}^{3+}, \mathrm{Fe}^{4+}, \mathrm{Mn}^{3+}, \mathrm{Mn}^{4+}$ are high spin (HS) ions, and $\mathrm{Ni}^{3+}, \mathrm{Ni}^{4+}$ and $\mathrm{Co}^{4+}$ low spin (LS) ions. $\mathrm{Co}^{3+}$ is, however, at the border, justifying why $\mathrm{Co}^{3+}$ can be found in both an intermediate (IS) and a LS state. In $\mathrm{LaCoO}_{3}$, $\mathrm{Co}^{3+}$ ions are in a non-magnetic LS state, whereas in the orthorhombic and cubic crystal structures they are in the IS state, characterized by an electronic transition from the $t_{2 g}$ to $e_{g}$ level. ${ }^{39,40}$ The magnetic transition arises as a consequence of a different O-M-O bond angle, the $\mathrm{M}-\mathrm{O}$ distance and partial charge transfer from $\mathrm{O} 2 \mathrm{p}$ to metal $3 \mathrm{~d}$ states. If the angle is close to $180^{\circ}$, there is a better overlap between the Co $3 \mathrm{~d}$ and $\mathrm{O} 2 \mathrm{p}$ orbitals, which increases crystal field splitting and renders $\mathrm{Co}^{3+}(\mathrm{LS})$ more stable. A decrease in the $\mathrm{M}-\mathrm{O}$ bond distance has the same effect. A partial charge transfer turns $\mathrm{Co}^{4+}(\mathrm{LS})$ in $\mathrm{CaCoO}_{3}$ to $\mathrm{Co}^{3+}$ (IS). $\mathrm{Co}^{3+}(\mathrm{LS})$ can also be thermally excited to higher spin states, e.g. $\mathrm{Co}^{3+}(\mathrm{LS})$ in $\mathrm{LaCoO}_{3}$ upon heating becomes first $\mathrm{Co}^{3+}(\mathrm{IS})$ at $35 \mathrm{~K}$ and then $\mathrm{Co}^{3+}(\mathrm{HS}) .{ }^{41,42}$ However, as DFT simulations are performed close to absolute zero, the minimum is obtained with $\mathrm{Co}^{3+}(\mathrm{LS})$.

We deduce the $e_{g}$ filling parameter from the ion's valence and spin ordering. The $e_{g}$ filling and ion valence are listed in the last two columns in Table 2. The $e_{g}$ value has previously been used as an activity descriptor for the oxygen evolution/reduction activity. ${ }^{10,76}$ We find that partial filling of the $\mathrm{e}_{\mathrm{g}}$ orbital can also describe electronic conductivity to a certain extent. Having $e_{g}=1$ is a necessary, but not a sufficient condition for ensuring electron transport. For instance, $\mathrm{Mn}^{3+}$ with nominal $e_{g}$ count of 1 is a nonconductive species, which is supported by the presence of JT distortions. ${ }^{27,77}$ In contrast, there are no $\mathrm{JT}$ distortions for $\mathrm{Ni}^{3+}$ owing to a delocalized nature of its $e_{g}$ electron.

The hybridization is not only determined by the $e_{g}$ filling, but also strongly influenced by the M-O-M bond angle. All the cubic systems with $e_{g}=1$ and straight M-O-M bond angles are electronically conductive. The interplay between the bond angle and $e_{g}$ filling is a good example of a cooperative effect between an electronic and geometric factor; which again underscores the complexity of these oxides. 
Table 2 Electronic, magnetic and geometric properties of selected oxides. SC stands for a semiconductor (band gaps values in brackets are in eVs). A, C and G, S(screw) and H(helical) letters stand for different types of magnetic ordering.

\begin{tabular}{|c|c|c|c|c|c|c|}
\hline $\begin{array}{l}\text { Perovskite } \\
\text { oxide }\end{array}$ & $\begin{array}{c}\text { Conduction } \\
\text { type }\end{array}$ & $\begin{array}{c}\text { Crystal } \\
\text { structure }^{1}\end{array}$ & $\begin{array}{c}\text { Magnetic } \\
\text { ordering }^{\mathrm{E}} \\
\text { rror! } \\
\text { Bookmark not } \\
\text { defined. }\end{array}$ & $\begin{array}{l}\text { Toleranc } \\
\text { e factor }\end{array}$ & $\begin{array}{c}\text { Ion } \\
\text { valence }\end{array}$ & $\begin{array}{c}\text { eg } \\
\text { electron } \\
\text { counts }^{3}\end{array}$ \\
\hline $\mathrm{LaCrO}_{3}$ & $\mathrm{SC}(3.40)^{35}$ & orthorhombic ${ }^{43}$ & G-AFM ${ }^{44}$ & 0.969 & 3 & 0 \\
\hline $\mathrm{LaMnO}_{3}$ & $\mathrm{SC}(1.10)^{35}$ & orthorhombic $^{45}$ & A-AFM ${ }^{46}$ & 0.954 & 3 (HS) & 1 \\
\hline $\mathrm{LaFeO}_{3}$ & $\mathrm{SC}(2.10)^{35}$ & orthorhombic $^{47}$ & G-AFM ${ }^{48}$ & 0.954 & 3 (HS) & 2 \\
\hline $\mathrm{LaCoO}_{3}$ & $\operatorname{SC}(0.30)^{35}$ & $\begin{array}{c}\text { corner- } \\
\text { hexagonal }^{49}\end{array}$ & $\mathrm{NM}^{50}$ & 1.003 & $3(\mathrm{LS})$ & 0 \\
\hline $\mathrm{LaNiO}_{3}$ & metal $^{51}$ & $\begin{array}{c}\text { corner- } \\
\text { hexagonal }^{52}\end{array}$ & $\mathrm{FM}^{53}$ & 0.996 & $3(\mathrm{LS})$ & 1 \\
\hline $\mathrm{LaCuO}_{3}$ & ${ }^{4}$ metal/SC ${ }^{54}$ & tetragonal ${ }^{55}$ & $\mathrm{FM}^{56}$ & 0.916 & 2 & 1 \\
\hline $\mathrm{CaCrO}_{3}$ & ${ }^{5}$ metal & orthorhombic $^{57}$ & C-AFM ${ }^{57}$ & 1.001 & 4 & 0 \\
\hline $\mathrm{CaMnO}_{3}$ & $\mathrm{SC}(3.07)^{58}$ & orthorhombic ${ }^{59}$ & G-AFM ${ }^{60}$ & 1.004 & 4 & 0 \\
\hline $\mathrm{CaFeO}_{3}$ & metal $^{61}$ & orthorhombic $^{61}$ & s-AFM ${ }^{61}$ & 0.976 & 3 (HS) & 1 \\
\hline $\mathrm{CaCoO}_{3}$ & metal $^{62}$ & cubic $^{62}$ & $\mathrm{FM}^{62}$ & 0.980 & 3 (IS) & 1 \\
\hline $\mathrm{SrCrO}_{3}$ & ${ }^{5}$ metallic & tetragonal/cubic $^{63}$ & C-AFM ${ }^{63}$ & 1.030 & $3-4$ & 0 \\
\hline $\mathrm{SrMnO}_{3}$ & $\operatorname{SC}(1.60)^{64}$ & face-hexagonal $^{64}$ & $\mathrm{AFM}^{64}$ & 1.041 & 4 & 0 \\
\hline $\mathrm{SrFeO}_{3}$ & metallic $^{65}$ & cubic $^{65}$ & s-AFM ${ }^{66}$ & 1.012 & 3 (HS) & 1 \\
\hline $\mathrm{SrCoO}_{3}$ & metallic $^{62}$ & cubic $^{62}$ & $\mathrm{FM}^{67}$ & 1.016 & 3 (IS) & 1 \\
\hline $\mathrm{BaCrO}_{3}$ & $\mathrm{SC}(0.38)^{68}$ & tetragonal $^{68}$ & $\mathrm{AFM}^{68}$ & 1.091 & $3-4$ & 0 \\
\hline $\mathrm{BaMnO}_{3}$ & $\mathrm{SC}^{69}$ & face-hexagonal $^{36}$ & $\mathrm{AFM}^{36}$ & 1.103 & $4(\mathrm{HS})$ & 0 \\
\hline $\mathrm{BaFeO}_{3}$ & half-metal $^{70}$ & cubic $^{71}$ & $\mathrm{~h}-\mathrm{AFM}^{71}$ & 1.072 & $3-4(\mathrm{HS})$ & $1-2$ \\
\hline $\mathrm{BaCoO}_{3}$ & $\mathrm{SC}^{72}$ & face-hexagonal $^{73}$ & $\mathrm{AFM}^{74}$ & 1.182 & $4(\mathrm{LS})$ & 0 \\
\hline $\mathrm{BaNiO}_{3}$ & $\mathrm{SC}^{75}$ & face-hexagonal $^{75}$ & $\mathrm{NM}^{75}$ & 1.132 & $4(\mathrm{LS})$ & 0 \\
\hline
\end{tabular}

1 Crystal structures are taken from literature under ambient conditions and magnetic structures at $\mathrm{T}=0 \mathrm{~K}$.

2 Tolerance factors are calculated from crystal ionic radii in ref. [105] using real ion valences.

3 The number of $e_{g}$ electrons is calculated from the ion's valence at $\mathrm{T}=0 \mathrm{~K}$ and preferred spin ordering.

$4 \mathrm{It}$ is still a matter of debate whether pristine $\mathrm{LaCuO}_{3}$ is a semiconductor or a metal

5 It is still a matter of debate whether $\mathrm{CaCrO}_{3}$ and $\mathrm{SrCrO}_{3}$ are insulating or metallic.

\subsubsection{Stability}

One major challenge in standard DFT calculations is how to compensate for a selfinteraction error. ${ }^{78}$ This spurious effect, which originates from the interaction of an electron with itself, is accompanied by charge delocalization. The charge delocalization is particularly challenging for a family of strongly correlated systems, whose electronic structures are characterized by many local features. The DFT $+\mathrm{U}$ approach is 
computationally the most affordable and widely accepted method for alleviating the selfinteraction error. It should be noted that $U$ is an empirical, computational parameter with no physical counterpart, whose choice varies greatly depending on which property is fitted and/or which implementation is used. ${ }^{79,80}$ This is well illustrated by the example of $\mathrm{LaMnO}_{3}$, where a range of U-values between 1.0 and $6.7 \mathrm{eV}$ have been reported. ${ }^{81-84}$ For reaction energetics, the most meaningful approach to deduce the $U$ value is to fit it to experimental enthalpies of known redox reactions (when available), which contain the same ions that are present in reaction under study. For calculating formation energies for, e.g., $\mathrm{LaMnO}_{3}$ against $\mathrm{MnO}_{2}$, the U-value should be fitted to an auxiliary reaction in which the oxidation state of Mn changes from $\mathrm{Mn}^{+3}$ to $\mathrm{Mn}^{+4}$, e.g. $\mathrm{Mn}_{2} \mathrm{O}_{3}+1 / 2 \mathrm{O}_{2} \rightarrow 2 \mathrm{MnO}_{2}$. Such an empirically fitted U would likely yield a better estimate of the formation energy for $\mathrm{LaMnO}_{3}$ in Eq. (3).

Formation energies computed at the DFT+U level, for three different $\mathrm{U}$ values are shown in Figure 2. As seen, for most of the catalysts, the formation energy is strongly dependent on the $\mathrm{U}$ value. The $\mathrm{U}$ correction has a different effect on ions in different oxidation states. There are three different ways in which formation energy can change depending on the oxidation state of the B cation in the perovskite $\left(O_{B}^{\text {per }}\right)$ and reference B oxide $\left(O_{B}^{r e f}\right)$. If $O_{B}^{\text {per }}<O_{B}^{\text {ref }}$, formation energy increases with $\mathrm{U}$, i.e. the catalyst material becomes more stable, if $O_{B}^{p e r}>O_{B}^{r e f}$ formation energy is found to decrease with $\mathrm{U}$ and if $O_{B}^{\text {per }}=O_{B}^{r e f}$ (e.g. $\mathrm{LaCrO}_{3}, \mathrm{LaFeO}_{3}, \mathrm{CaMnO}_{3}, \mathrm{BaNiO}_{3}$, etc.), formation energy becomes largely $\mathrm{U}$ independent. The effect of $U$ on formation energies is explained by the following: imposing occupation of $3 \mathrm{~d}$ orbitals by applying the $\mathrm{U}$ correction shifts the occupied $3 \mathrm{~d}$ orbitals further away from the Fermi level. Consequently, the covalence between the transition metal $3 \mathrm{~d}$ and O $2 p$ orbitals reduces, which causes the total energy of the system to increase. The increase is more pronounced for ions in higher oxidation states, because $3 \mathrm{~d}$ orbitals have higher energies being closer to the core electron states and a further downshift will lead to a larger energy increase in comparison to ions in lower oxidation states. Applying the same $U$ on $\mathrm{Mn}^{3+}$ in $\mathrm{LaMnO}_{3}$ and $\mathrm{Mn}^{4+}$ in $\mathrm{MnO}_{2}$ shifts the total energy of the latter more, which effectively increases the $\mathrm{LaMnO}_{3}$ formation energy. The same argument can be used to explain the reduction in formation energy when $O_{B}^{\text {per }}>O_{B}^{\text {ref }}$. 


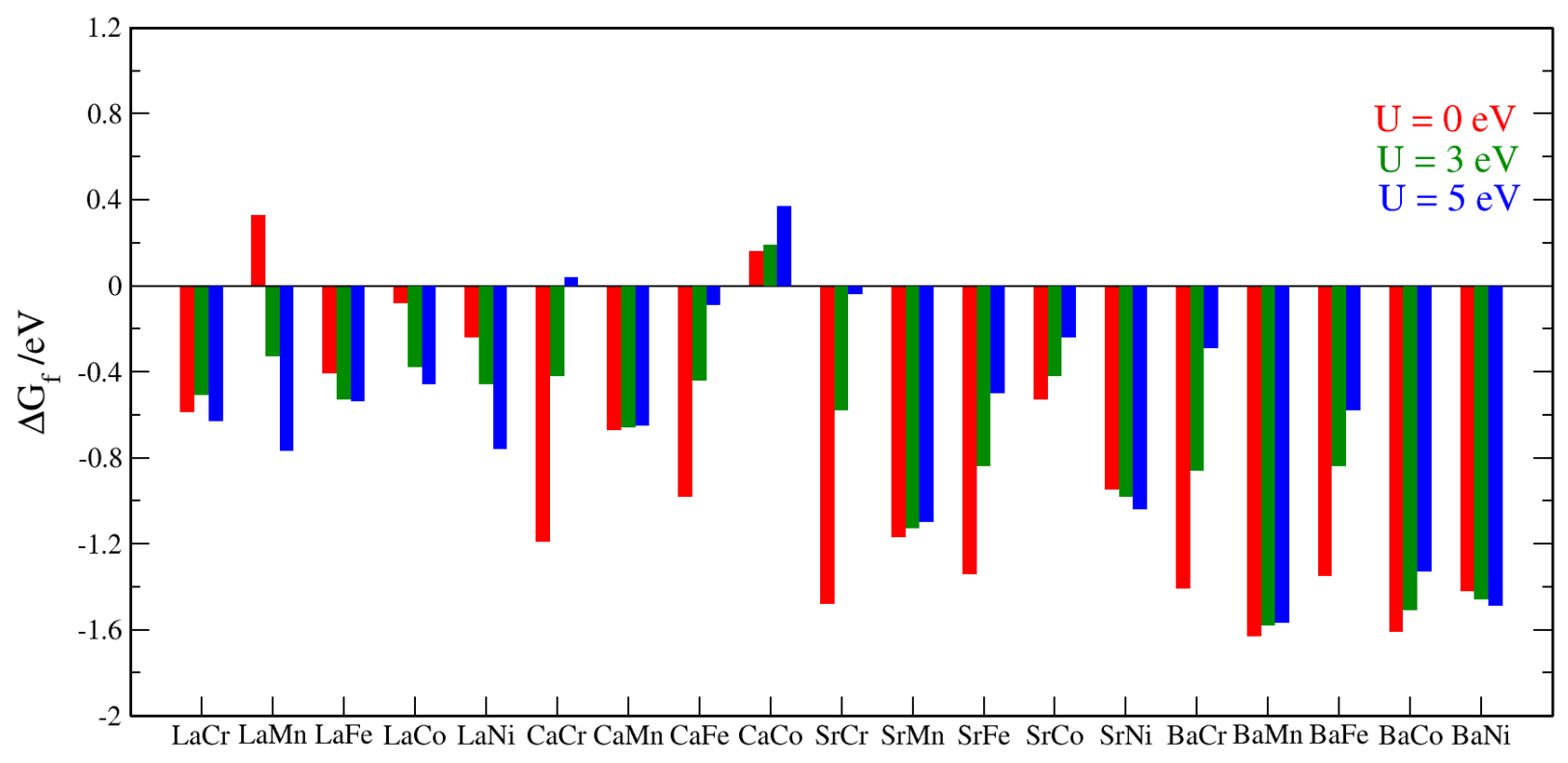

Figure 2 Calculated heats of formation with $D F T+U$ at three different $U$ values. $\mathrm{O}_{3}$ in the oxide formulas on $x$-axis is omitted for clarity.

Computationally more demanding hybrid functional calculations, typically those of the HSE flavour are now often being used as benchmark calculations to evaluate the DFT+U results. Instead of artificially enforcing occupation with the $U$ parameter, electron correlations in hybrid functionals are accounted for by introducing a certain amount of Fock (exact) exchange, $\alpha$ in the short-ranged electron-electron interactions. Although electron correlations are more naturally taken into account by mixing the PBE and Fock exchange, the results are also affected by the choice of $\alpha .{ }^{8527}$ In order to investigate how much the results change with $\alpha$, we have calculated formation energies of the perovskite oxides at discrete values of $\alpha=0,0.15,0.25$ and 0.35 (cf. Figure 3).

As seen in Figure 3, formation energies change even more drastically in the investigated $\alpha=0-0.35$ range than they change with $\mathrm{U}$ when $O_{B}^{\text {per }} \neq O_{B}^{\text {ref }}$. In the $O_{B}^{\text {per }}=O_{B}^{\text {ref }}$ case, the results are independent of $\alpha$ and similar to those in DFT $+U$ calculations. An equally strong dependence of formation energies on $\alpha$ as on $U$ suggests that $\alpha$ should be fitted, e.g. to reaction enthalpies, similarly as $U$ in DFT $+U$ calculations. The necessity for adjusting $\alpha$ brings into discussion whether standard HSE calculations should always be used as robust benchmarks. 


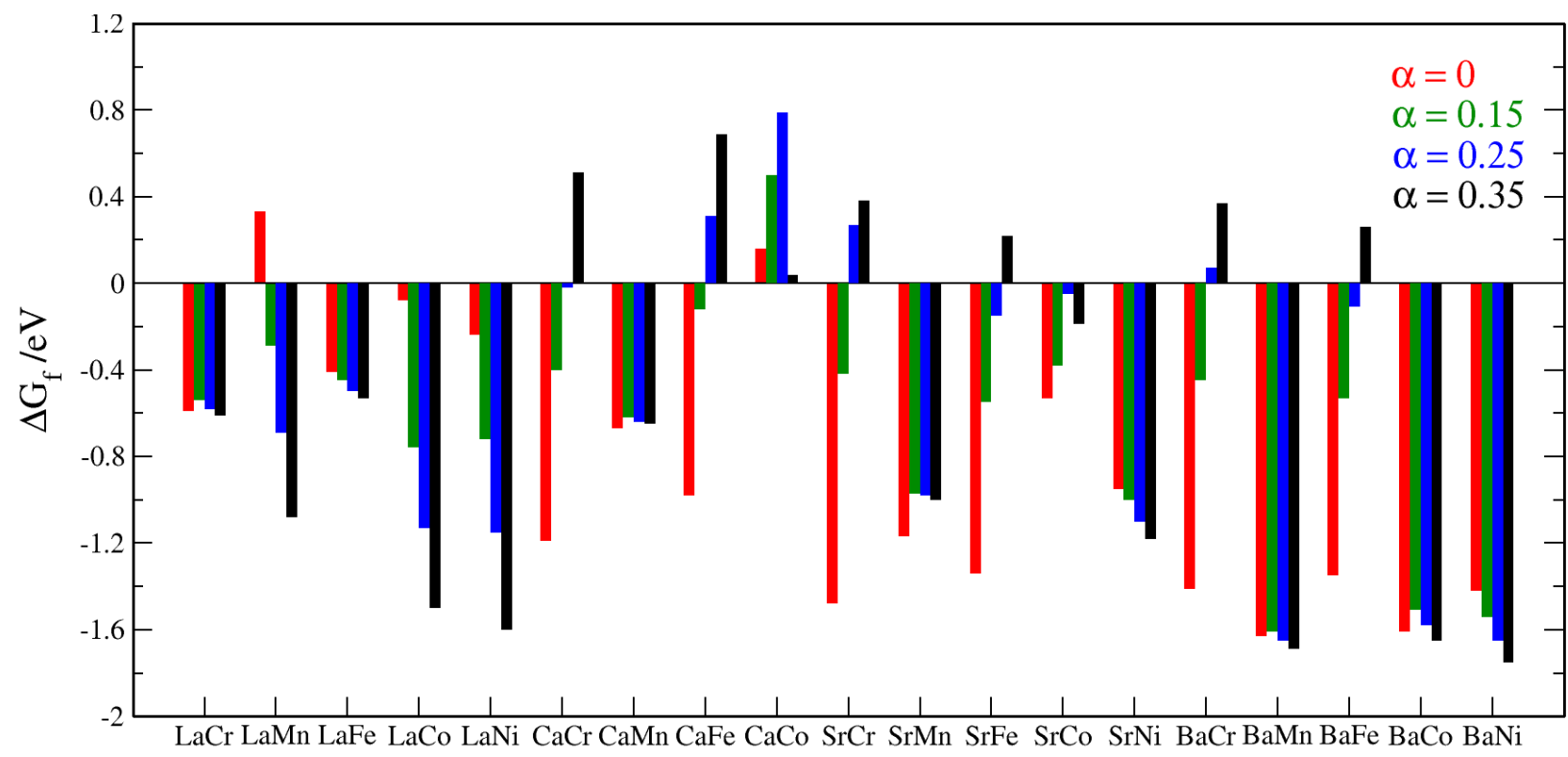

Figure 3 Calculated heats of formation with HSE at three different mixing parameters $(\alpha) . O_{3}$ in the oxide formulas on $x$-axis is omitted for clarity.

Although it is not possible to discuss stability in absolute terms using results in Figure 2 and 3, some general trends can still be inferred, e.g. perovskite oxides with face-shared octahedra $\left(\mathrm{SrMnO}_{3}, \mathrm{SrNiO}_{3}, \mathrm{BaMnO}_{3}, \mathrm{BaCoO}_{3}\right.$ and $\left.\mathrm{BaNiO}_{3}\right)$ have the highest formation energies. It should be noted that formation energy is not the only criterion for having a stable system. Electrolysis and most battery cells are open systems that feed on air, and where there is air there is also carbon dioxide in ppm amounts. Alkaline earth oxides in the presence of $\mathrm{CO}_{2}$ tend to form carbonates, which are detrimental for the alkaline electrolysis/battery cell. ${ }^{86-88}$ Formation of carbonates is always favoured because of high heats of formation (1.62, 2.13 and $2.56 \mathrm{eV}$ for $\mathrm{Ca}, \mathrm{Sr}$ and $\mathrm{Ba}$ carbonates, respectively). From that perspective, La compounds and in particular $\mathrm{LaMnO}_{3}, \mathrm{LaNiO}_{3}$ and $\mathrm{LaCoO}_{3}$, are better choices for oxygen evolution electrocatalysis.

Furthermore, certain compounds, such as $\mathrm{CaCrO}_{3}, \mathrm{CaFeO}_{3}, \mathrm{CaCoO}_{3}, \mathrm{SrCrO}_{3}, \mathrm{SrFeO}_{3}$, $\mathrm{SrCoO}_{3}, \mathrm{BaCrO}_{3}$ and $\mathrm{BaFeO}_{3}$ have close to zero or even negative heats of formations, which is almost equivalent to the list of materials $\mathrm{CaCrO}_{3}{ }^{89}, \mathrm{SrCrO}_{3}{ }^{89}, \mathrm{CaCoO}_{3}{ }^{29}, \mathrm{SrCoO}_{3}{ }^{30}$, $\mathrm{CaFeO}_{3}{ }^{90}, \mathrm{SrFeO}_{3}{ }^{71}$ and $\mathrm{BaFeO}_{3}{ }^{71}$ whose synthesis is possible only under elevated temperatures and pressures of several GPa. Such extreme conditions are necessary to force oxygen into the crystal lattice of oxygen deficient precursors. It is therefore highly unlikely that any of these oxides will be stable in the long-run in an electrochemical environment. Many of these materials belong to a special class of charge transfer insulators with negative 
charge transfer energy, $\Delta$. The $\Delta$ measures the distance between the $\mathrm{O} 2 p$ and metal $3 d$ states. In the case $3 d$ orbitals have higher binding energies than the $\mathrm{O} 2 p$ orbitals, $\Delta$ becomes negative, which instigates a spontaneous charge transfer from oxygen to metal $3 d$ states. As a result, ion valences become different than the nominal values, i.e. $\mathrm{O}^{2-}$ and $\mathrm{B}^{\mathrm{n}+}$ become $\mathrm{O}^{(2-}$ ${ }^{\delta)-}$ and $\mathrm{B}^{(\mathrm{n}-\delta)^{+}}$, respectively. The positive charge on $\mathrm{O}^{2-}$ is usually denoted as a ligand hole $L$. Antibonding orbitals formed via hybridization of the $\mathrm{O} 2 p$ and metal $3 d$ states have more $\mathrm{O}$ $2 p$ character because the $\mathrm{O} 2 p$ states are closer in energy to the Fermi level, which becomes important if system is doped by a lower valent element (vide supra). Assuming that positions of the $\mathrm{O} 2 p$ and occupied metal $3 d$ orbitals are well described by their respective centres, $\varepsilon_{\mathrm{p}}$ and $\varepsilon_{\mathrm{d}}$, increasing their relative separation, $\varepsilon_{\mathrm{p}}-\varepsilon_{\mathrm{d}}$, increases the $\Delta$. In turn, this makes the crystal less stable because the electrostatic interaction, that is, the Madelung energy between $\mathrm{O}^{(2-\delta)-}$ and $\mathrm{B}^{(\mathrm{n}-\delta)+}$ is lower than that between $\mathrm{O}^{2-}$ and $\mathrm{B}^{\mathrm{n}+} \cdot{ }^{91} \mathrm{~A}$ decrease in the activity with $\varepsilon_{\mathrm{p}}$ approaching the Fermi level is experimentally well documented. ${ }^{14,91}$ The $\Delta$-value increases with the ion's oxidation state because the d states are pulled further down in comparison to O $2 \mathrm{p}$ states (cf. $\mathrm{Co}^{3+}$ (IS) in $\mathrm{CaCoO}_{3}$ ). For a more detailed discussion about $\Delta$ and its implications we refer to Ref. ${ }^{92}$. Charge transfer has been experimentally observed for $\mathrm{SrFeO}_{3}, \mathrm{CaCoO}_{3}$ and $\mathrm{BaFeO}_{3}$, in which $\mathrm{Co}$ and $\mathrm{Fe}$ are closer to the +3 than +4 nominal oxidation state. ${ }^{92}$ Another effect arising from negative $\Delta$ is charge disproportionation. Typical examples are $\mathrm{Fe}^{4+}$ in $\mathrm{CaFeO}_{3}{ }^{56,84}$ and $\mathrm{CaCu}_{3} \mathrm{Fe}_{4} \mathrm{O}_{12}{ }^{93}$, and $\mathrm{Ni}^{3+}$ in some lanthanide

nickelates. ${ }^{61,94,95}$ Charge disproportionation in $\mathrm{CaFeO}_{3}$ is not a consequence of electron transfer between two $\mathrm{Fe}^{4+}$ (i.e. the formation of a $\mathrm{Fe}^{3+}-\mathrm{Fe}^{5+}$ pair), but between $\mathrm{Fe}^{4+}$ and $\mathrm{O} 2 p$ states, which creates $2 \mathrm{Fe}^{3+}$ and two ligand holes $L^{2}$ on oxygen. ${ }^{93,94}$

La is likely the best choice for A element, because 1) it does not form carbonates, 2) La perovskites, in particular $\mathrm{LaCoO}_{3}$ and $\mathrm{LaNiO}_{3}$ seem to be stable catalysts and 3) the chances for charge transfer are much smaller when cation $B$ is in the +3 oxidation state.

\subsubsection{Activity}

Here, we compute the OER activities using the computational hydrogen electrode (CHE) method for the subset of La perovskites. ${ }^{32}$ The difference between the $\mathrm{O}$ and $\mathrm{OH}$ binding free energies was shown to be a good descriptor for the oxygen evolution activity. ${ }^{17}$ Herein, the reaction overpotentials are derived by calculating adsorption free energies of all different reaction intermediates (not only $\mathrm{O}$ and $\mathrm{OH}$ ) and identifying the step with the highest 
thermochemical free energy barrier. We examine four different reaction mechanisms, in which we assume a concerted proton-electron transfer. Exploring the entire potential energy landscape including pathways where proton and electron transfers occur in separate steps, ${ }^{96}$ is beyond the scope of the present study.

Prior to the activity analysis, we first determine the stable surface termination. This is paramount because the reaction path and the reaction overpotential might change with the surface termination, which is a function of potential. We calculate surface terminations at $\mathrm{U}$ $=5 \mathrm{eV}$, which corresponds approximately to average $\mathrm{U}$ values reported in the literature for La-perovskites. ${ }^{97-99}$ For the unit cell size used in this work, there are four surface oxygen atoms. We find that even at OER conditions (1.70 V vs RHE), most of the surfaces are partially reduced and terminated with hydroxyl groups (cf. Note 1 in the Electronic Supplementary Information (ESI)). It should be noted that we determine the surface termination for $\mathrm{U}=5 \mathrm{eV}$ and $\alpha=0.25$ and then assume it to be the same for other $\mathrm{U}$ and $\alpha$ values, respectively.

We distinguish among four different reaction mechanisms, two of those are taking place on a single site and two involve two adjacent sites. In the first mechanism, oxygen evolution takes place through a series of oxidation steps beginning with the first hydroxyl discharge to the surface (step 1). In the next step, the surface $\mathrm{OH}$ is deprotonated to the ${ }^{*} \mathrm{O}$ intermediate. ${ }^{*} \mathrm{OOH}$ is formed after the second hydroxyl discharge to the ${ }^{*} \mathrm{O}$ (step 3). The second deprotonation step makes the ${ }^{*} \mathrm{O}_{2}$ (step 4) which subsequently desorbs from the surface.

$$
\begin{aligned}
& { }^{*}+\mathrm{OH}^{-} \rightarrow{ }^{*} \mathrm{OH}+\mathrm{e}^{-} \\
& { }^{*} \mathrm{OH}+\mathrm{OH}^{-} \rightarrow{ }^{*} \mathrm{O}+\mathrm{H}_{2} \mathrm{O}+\mathrm{e}^{-} \\
& { }^{*} \mathrm{O}+\mathrm{OH}^{-} \rightarrow{ }^{*} \mathrm{OOH}+\mathrm{e}^{-} \\
& { }^{*} \mathrm{OOH}+\mathrm{OH}^{-} \rightarrow \mathrm{O}_{2}(\mathrm{~g})+\mathrm{H}_{2} \mathrm{O}+\mathrm{e}^{-}
\end{aligned}
$$

We noticed that ${ }^{*} \mathrm{OOH}$ on $\mathrm{LaFeO}_{3}$ and $\mathrm{LaMnO}_{3}$ spontaneously decomposes to ${ }^{*} \mathrm{O}_{2}$ and a proton which adsorbs on a free lattice oxygen site.

$$
{ }^{*} \mathrm{OOH}+{ }^{*} \rightarrow \mathrm{O}_{2}(\mathrm{~g})+{ }^{*} \mathrm{H}
$$

The subsequent proton desorption is downhill in free energy at $\mathrm{U}=1.70 \mathrm{~V}$, since pertinent $\mathrm{LaFeO}_{3}$ and $\mathrm{LaMnO}_{3}$ surfaces are *H-free at that potential. 
The second pathway involves lattice oxygen. ${ }^{91}$ The reaction starts with the same steps 1 and 2 , then the $\mathrm{O}_{2}$ desorbs from the surface leaving a surface oxygen vacancy.

${ }^{*} \mathrm{O} \rightarrow \mathrm{O}_{2}(\mathrm{~g})+{ }^{*} \mathrm{O}_{\mathrm{vac}}$

This step is not potential dependent, but might enter into the reaction rate through the pre-exponential factor. Moreover, if the desorption barrier is prohibitively high then the reaction will be inhibited regardless of the potential. $\mathrm{O}_{2}$ desorption is followed by step 6 and 7 after which the initial surface is restored:

${ }^{*} \mathrm{O}_{\mathrm{vac}}+\mathrm{OH}^{-} \rightarrow{ }^{*} \mathrm{H}+\mathrm{e}^{-}$

${ }^{*} \mathrm{H}+\mathrm{OH}^{-} \rightarrow{ }^{*}+\mathrm{H}_{2} \mathrm{O}+\mathrm{e}^{-}$

In the third reaction mechanism, steps 1 and 2 are followed by steps 8 and 9 before two surface oxygen atoms recombine to make $\mathrm{O}_{2}(\mathrm{~g})$.

${ }^{*} \mathrm{O}+{ }^{*}+\mathrm{OH}^{-} \rightarrow{ }^{*} \mathrm{O}+{ }^{*} \mathrm{OH}+\mathrm{e}^{-}$

${ }^{*} \mathrm{O}+{ }^{*} \mathrm{OH}+\mathrm{OH}^{-} \rightarrow 2^{*} \mathrm{O}+\mathrm{H}_{2} \mathrm{O}+\mathrm{e}^{-}$

$2^{*} \mathrm{O} \rightarrow{ }^{*} \mathrm{O}_{2} \rightarrow \mathrm{O}_{2}(\mathrm{~g})+{ }^{*}$

(step 10)

A fourth possible pathway starts as well with step 1 , which is repeated twice before a chemical disproportionation step converts two neighbouring hydroxyls to oxygen and water.

$2^{*} \mathrm{OH} \rightarrow{ }^{*} \mathrm{O}+\mathrm{H}_{2} \mathrm{O}$

(step 11)

${ }^{*} \mathrm{O}_{2}$ desorbs from the surface through step (5) and the ${ }^{*} \mathrm{O}_{\mathrm{vac}}$ is removed through steps 6 and 7 to complete the thermodynamical cycle. The probability of this reaction pathway is very low due to a large distance between two adjacent B sites on which $\mathrm{OH}$ adsorbs. ${ }^{100}$ Therefore, we decided to exclude this pathway from further analysis. In Note 2 in the ESI, we list free energy values for steps 1 to 10 . We find that either step 1 or step 2 is the potential determining step (PDS) on all the catalysts studied herein. As the first, second and third reaction mechanism share the same steps 1 and 2, the reaction overpotential associated with the $2^{\text {nd }}$ and $3^{\text {rd }}$ pathways cannot be lower than the overpotential from the $1^{\text {st }}$ pathway. This suggests that the three reaction mechanisms might run in parallel. Nonetheless, the $2^{\text {nd }}$, i.e. lattice oxygen pathway can be excluded for all the catalysts but $\mathrm{LaCoO}_{3}$ because the kinetic barrier in step 5 is exceedingly high (above $1 \mathrm{eV}$ ). Also, the PDS (step 8 or 9) in the 
$3^{\text {rd }}$ reaction mechanism is usually higher than step 1 or step 2 , suggesting that the reaction proceeds via the first reaction mechanism on a single site. The oxygen evolution cycle for the $1^{\text {st }}$ reaction mechanism is illustrated in Figure 4. The changes in the reaction overpotential as a function of $U$ in DFT $+U$ and as a function of $\alpha$ in HSE calculations are shown in Figure 5. The overpotential is inferred by subtracting the equilibrium potential for oxygen evolution $(1.23 \mathrm{~V})$ from the potential corresponding to the step with the highest free energy barrier, i.e the largest $\Delta \mathrm{G}_{1-4}$ in Table 3.

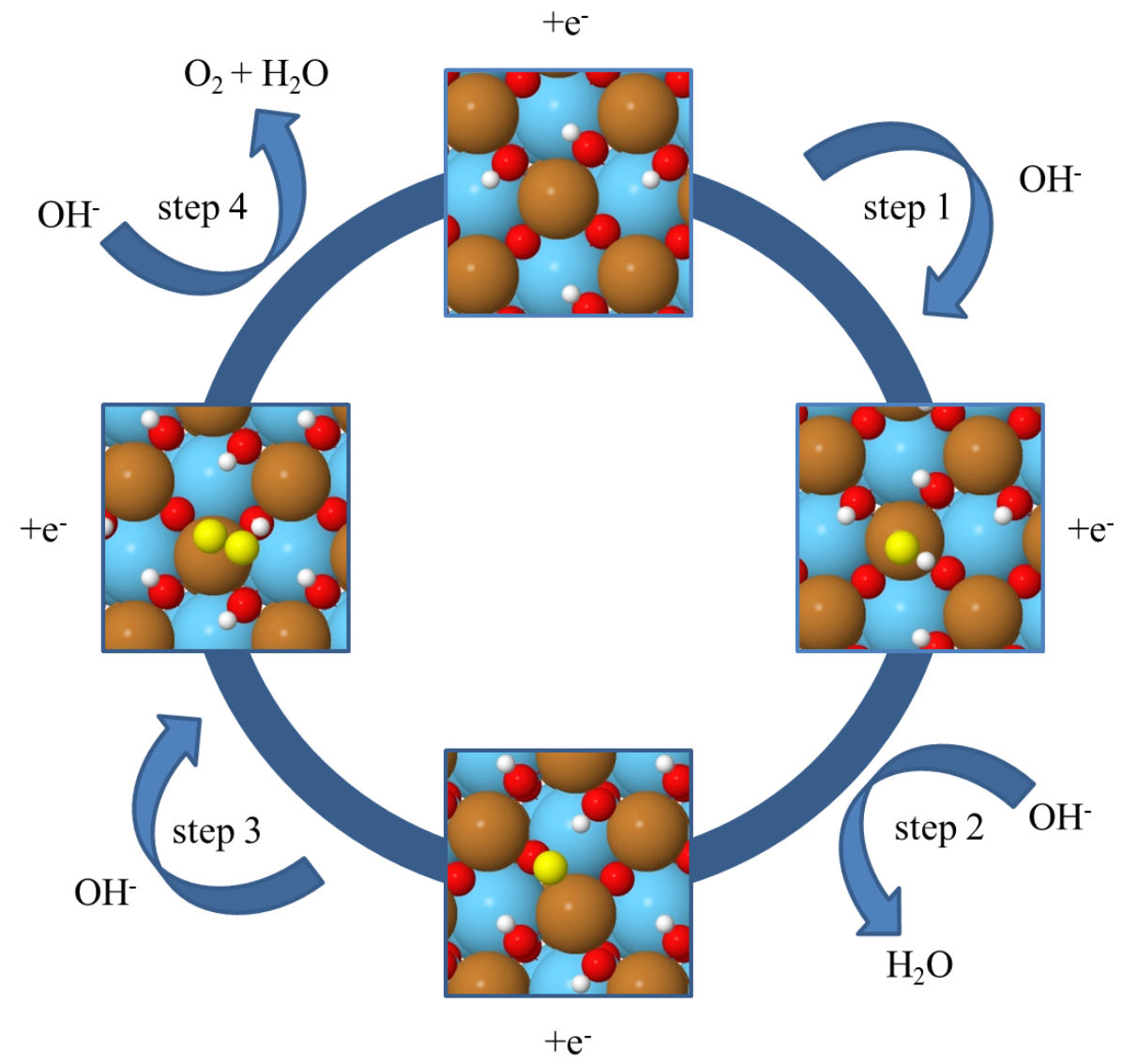

Figure 4 Illustration of the oxygen evolution mechanism on the example of $\mathrm{LaNiO}_{3}$. Blue, brown, red and white balls are $\mathrm{La}, \mathrm{Ni}, \mathrm{O}$ and $\mathrm{H}$ atoms, respectively. Oxygen atoms in reaction intermediates are highlighted in yellow. 
a)

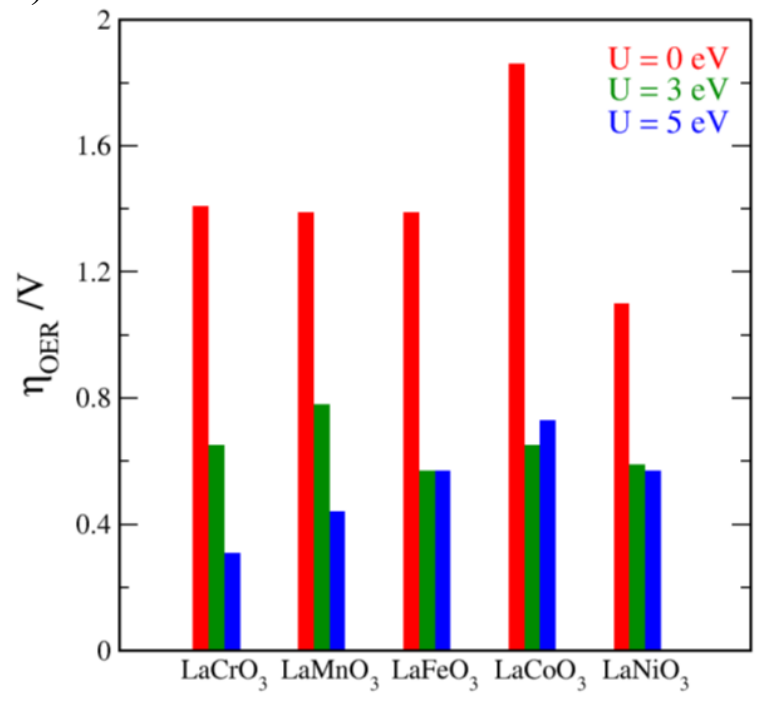

b)

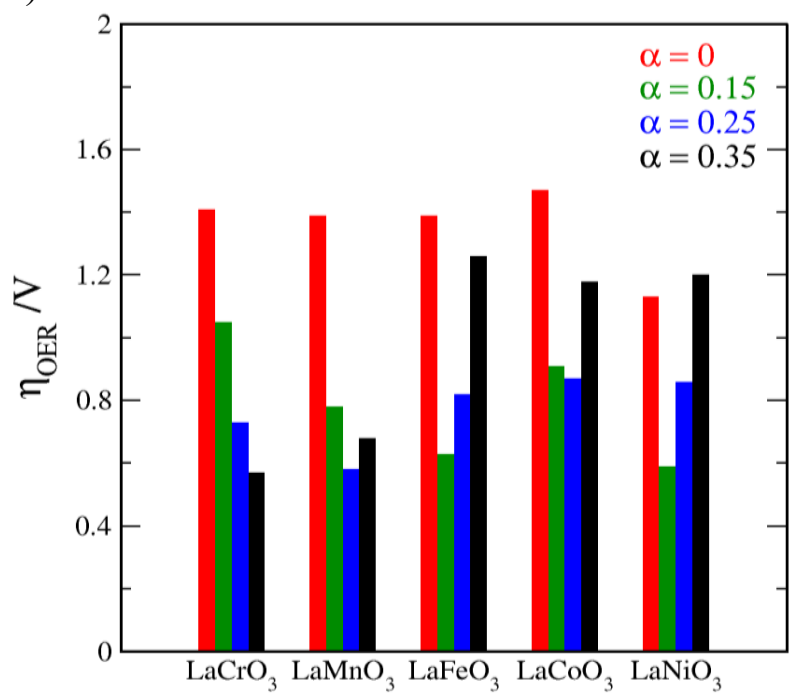

Figure 5 Calculated reaction overpotentials for the oxygen evolution reaction, $\eta_{O E R}$, at different a) $U$ and b) $\alpha$ values in DFT $U$ and HSE calculations, respectively. Selecting $U=0 \mathrm{eV}$ in DFT $U$ and $\alpha=0$ in HSE calculations is equivalent under condition that the termination is the same.

As seen in Figure 5 there is a large difference in the reaction overpotential with both $U$ and $\alpha$, which can be assigned to changes in the $\mathrm{B}$ cation valence during electrochemical reaction. The reaction overpotentials for $\mathrm{LaCoO}_{3}$ in Figure 5a and $5 \mathrm{~b}$ have different values at $\mathrm{U}=0 \mathrm{eV}$ and $\alpha=0$, respectively because of the different terminations, that is, the number of hydroxyl species on the surface (cf. Note 1 in the ESI). It should further be noted that $\mathrm{LaCoO}_{3}$ is modelled with $\mathrm{Co}^{3+}$ in the LS state. The $\mathrm{Co}^{3+}$ (IS) prevailing at room temperature would likely give different reaction energetics, however, given the large U-dependence, it is not possible to compare the results for the two spin states. We make a comparative analysis by listing the adsorption energies of different reaction intermediates on $\mathrm{LaCrO}_{3}, \mathrm{LaMnO}_{3}$ and $\mathrm{LaNiO}_{3}$ in Table $3 .^{32}$ The free energy values for steps 1-4 using different $U$ and $\alpha$ parameters are summarized in Note 2 in the ESI. 
a)

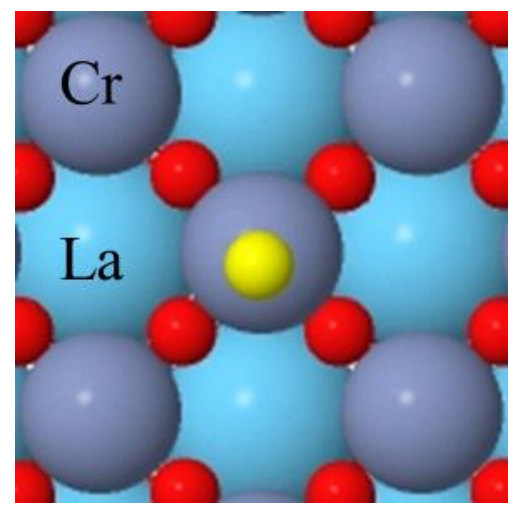

b)

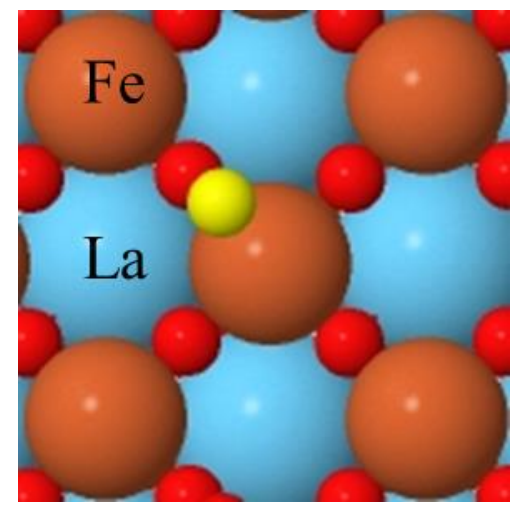

Figure 6 Oxygen intermediate binds a) on-top of a $\mathrm{Cr}$ ion in $\mathrm{LaCrO}_{3}$ and b) in a lateral site on $\mathrm{LaFeO}_{3}$, where it makes peroxo species with lattice oxygen. Light blue, grey, brown and red balls are $\mathrm{La}, \mathrm{Cr}, \mathrm{Fe}$ and $\mathrm{O}$ atoms, respectively.

$\mathrm{OH}^{*}$ in an-top position increases the oxidation state of a $\mathrm{B}$ metal ion by 1 . On the other hand, $\mathrm{O}^{*}$ increases the oxidation state by two if adsorbed on-top (Figure 6a) or keeps the same oxidation state if adsorbed between a surface oxygen and metal ion site (Figure 6b), where it creates a peroxo species with the lattice oxygen. The latter happens on $\mathrm{LaFeO}_{3}$ and $\mathrm{LaMnO}_{3}$, where the presence of peroxo species is discerned by the O-O bond length (1.47 $\AA)$ and charge on the oxygen ions. In the presence of peroxo species the valence of surface $\mathrm{Mn}$ and $\mathrm{Fe}$ is the same as those on the pure slab, explaining why $\Delta E\left(^{*} O\right)$ in Table 3 is $\mathrm{U}$ independent. On $\mathrm{LaCrO}_{3}$, the $\mathrm{O}$ adsorbs in the on-top position, thereby changing the oxidation state of $\mathrm{Cr}$ from +3 to nearly +5 . $\mathrm{Cr}^{5+}$ forms a stable +5 oxide $\left(\mathrm{Cr}_{2} \mathrm{O}_{5}\right)$ in contrast to the other transition metals. As a result of the change in the oxidation state, $\Delta E\left({ }^{*} O\right)$ for $\mathrm{LaCrO}_{3}$ is U-dependent; it changes from 0.80 to $2.82 \mathrm{eV}$ in the $\mathrm{U}=0-5 \mathrm{eV}$ range. The same valence argument can be used to explain why $\triangle E(O H)$ and $\triangle E(O O H)$ change with $\mathrm{U}$. On $\mathrm{LaFeO}_{3}$ and $\mathrm{LaMnO}_{3}, \triangle E(O H)$ changes with $\mathrm{U}$ as well, but surprisingly $\triangle E\left({ }^{*} O O H\right)$ is found to be U-independent. By examining more closely the structure we realized that $\mathrm{OOH}$ underwent a spontaneous decomposition via ${ }^{*} \mathrm{OOH} \rightarrow{ }^{*} \mathrm{O}_{2}{ }^{-}+\mathrm{H}^{+}$to an adsorbed superoxo ${ }^{*} \mathrm{O}_{2}{ }^{-}$ characterized by a O-O bond length of approximately $1.30 \AA$ and a proton, which adsorbs on an empty lattice oxygen site. The decomposition and presence of superoxo ${ }^{*} \mathrm{O}_{2}^{-}$keeps the oxidation state of surface ion the same as on the pure slab, which results in small variations of adsorption energies with $U$. We note here that this is not the first report on the effect of $U$ on reaction energetics. ${ }^{80,101}$ In a recent study, the authors have reported a dramatic change of approximately $2.0 / 1.0 \mathrm{eV}$ in the reaction free/activation energy for formaldehyde 
dehydrogenation on $\mathrm{CeO}_{2} \cdot{ }^{80}$ From our perspective, these large changes can be attributed to the changes in the oxidation state of Ce along the reaction path.

The same tendencies and even larger changes are observed for changing $\alpha$ in the investigated $0-0.35$ range. Again, free energies are strongly dependent on the oxidation state of B cations, which results in large fluctuations in the calculated overpotentials. Consequently, we arrive at the same conclusion as in the case of the formation energies: HSE calculations do not seem to improve sufficiently the DFT+U results for the OER overpotentials to justify the excess computational cost.

Obtaining an accurate estimate of the reaction overpotential is difficult because 1) there are 4 different electrochemical steps involved in the OER, whereas $U$ (or $\alpha$ ) are inferred by fitting to a single reaction; 2) oxidation states of surface B cations do not always change as expected; they are both dependent on the nature of the cation and oxygen intermediate (cf. Table 3); 3) most of late transition metal perovskites are charge transfer insulators suggesting that lattice $\mathrm{O} 2 \mathrm{p}$ states can also play a role in the reaction, such that upon oxidation, the holes may localize on the $\mathrm{O} 2 \mathrm{p}$ states; and 4) the possible charge transfer from O $2 p$ to metal $3 \mathrm{~d}$ states, especially in the case of ions that are in the +4 or higher oxidation state.

To put these results into a broader perspective, the changes in the formation energies and reaction overpotentials reported herein are not solely restricted to this particular class of materials, but may likely be pervasive throughout the class of strongly correlated oxides, where standard DFT approaches do not provide a satisfactory description of the electronic structure. We are currently pursuing two avenues to remedy this problem, i.e. a computationally low-cost approach in which reaction energetics can be made U-independent with the help of thermochemical tables and secondly, to apply a higher-level method, viz., Møller-Plesset second order perturbation (MP2) theory using a computationally affordable linear combination of atomic orbitals (LCAO) basis set to describe the wavefunctions. 
Table 3 Adsorption energies in units of electron volts at three different $U$ and $\alpha$ values. Valences of $B$ cations taken at $U=5 \mathrm{eV}$ and $\alpha=0.25$ are shown in $V(B)$ columns. On the pure slab, the valence is always 3.

\begin{tabular}{|c|c|c|c|c|c|c|c|c|c|c|c|c|}
\hline & \multicolumn{4}{|c|}{$\mathrm{LaCrO}_{3}$} & \multicolumn{4}{|c|}{$\mathrm{LaMnO}_{3}$} & \multicolumn{4}{|c|}{$\mathrm{LaFeO}_{3}$} \\
\hline $\mathrm{U}(\mathbf{P B E}+\mathrm{U})$ & $\mathbf{0}$ & 3 & 5 & $V(B)$ & $\mathbf{0}$ & 3 & 5 & $V(B)$ & $\mathbf{0}$ & 3 & 5 & $V(B)$ \\
\hline$\Delta \mathbf{E}\left({ }^{*} \mathbf{O H}\right)$ & 0.02 & 0.64 & 0.98 & $3-4$ & 0.29 & 0.91 & 1.26 & $3-4$ & 0.19 & 0.99 & 1.45 & 4 \\
\hline$\Delta \mathbf{E}\left({ }^{*} \mathbf{O}\right)$ & 0.80 & 2.02 & 2.82 & $4-5$ & 3.20 & 3.22 & 3.23 & 3 & 3.11 & 3.09 & 3.14 & 3 \\
\hline \multirow[t]{2}{*}{$\Delta \mathrm{E}\left({ }^{*} \mathrm{OOH}\right)$} & 2.96 & 3.55 & 3.91 & $3-4$ & 3.23 & 3.13 & 4.09 & 3 & 3.85 & 3.86 & 3.82 & 3 \\
\hline & \multicolumn{4}{|c|}{$\mathrm{LaCrO}_{3}$} & \multicolumn{4}{|c|}{$\mathrm{LaMnO}_{3}$} & \multicolumn{4}{|c|}{$\mathrm{LaFeO}_{3}$} \\
\hline$\alpha$ (HSE) & 0.15 & 0.25 & 0.35 & $\begin{array}{l}\mathrm{V}(\mathbf{B}) \\
\end{array}$ & 0.15 & 0.25 & 0.35 & $\mathbf{V}(\mathbf{B})$ & 0.15 & 0.25 & 0.35 & $V(B)$ \\
\hline$\Delta \mathrm{E}\left({ }^{*} \mathrm{OH}\right)$ & 0.69 & 0.99 & 1.43 & 4 & 1.01 & 1.46 & 1.56 & $3-4$ & 1.16 & 1.70 & 2.14 & 4 \\
\hline$\Delta \mathbf{E}\left({ }^{*} \mathbf{O}\right)$ & 2.05 & 2.74 & 3.53 & $4-5$ & 3.32 & 3.23 & 3.30 & 3 & 3.33 & 3.44 & 3.53 & 3 \\
\hline$\Delta \mathrm{E}\left({ }^{*} \mathrm{OOH}\right)$ & 3.98 & 4.35 & 4.76 & $3-4$ & 3.52 & 3.43 & 3.35 & 3 & 4.29 & 4.42 & 4.51 & 3 \\
\hline
\end{tabular}

\subsubsection{Electronic conductivity}

A major challenge associated with GGA-level DFT calculations is a considerable underestimation of the band gap due to the self-interaction correction. ${ }^{78}$ The problem can to some extend be resolved by applying the on-site U Coulomb correction, which opens the band gap. Once the gap is opened and material becomes a semiconductor, a further increase in $U$ will only widen the band-gap. Thus, increasing $U$ above the critical value at which the gap opens up can only have a quantitative effect on the conductivity. Exceptions are polaron states, because their position is quite sensitive to the width of the gap. ${ }^{102}$ For the systems studied herein, we find a small change in the electronic structure at $\mathrm{U}=3$ and $5 \mathrm{eV}$, even for systems with polarons. We do not observe large qualitative changes in the electronic structure for pure La-perovskites when HSE is used (cf. Note 3 in the ESI). Therefore in the following we draw conclusions about electron conductivity on the basis of DOS plots inferred using a $\mathrm{U}$ value of $5 \mathrm{eV}$ in DFT + U calculations.

Here, we explore doping as an effective means to improve the electronic conductivity. In Figure 7, we show a conductivity map for doped La perovskites with a general formula $\mathrm{La}_{\mathrm{x}} \mathrm{A}^{\prime}{ }_{1-\mathrm{x}} \mathrm{B}_{\mathrm{y}} \mathrm{B}^{\prime}{ }_{1-\mathrm{y}} \mathrm{O}_{3},\left(\mathrm{x}, \mathrm{y}=1 / 4\right.$ for orthorhombic and $1 / 6$ for hexagonal cell), where $\mathrm{A}^{\prime}=(\mathrm{Ca}$, $\mathrm{Sr}$ and $\mathrm{Ba})$ and $\mathrm{B}^{\prime}=(\mathrm{Cr}, \mathrm{Mn}, \mathrm{Fe}, \mathrm{Co}, \mathrm{Ni}$ and $\mathrm{Cu})$ are changed independently of each other. We set the $\mathrm{U}$-value to $5 \mathrm{eV}$ which is approximately an average $\mathrm{U}$ value reported for these 
compounds. ${ }^{41}$ We infer the conductivity type by carefully examining the DOS, especially regarding the position of the Fermi level with respect to the valence and conduction band edges, and magnetic moments of host and dopant metal cations. The following discussion is based mainly on Notes 3 and 4 in the ESI, wherein we plot DOS and tabulate magnetic moments of host and dopant elements for the investigated subset of doped La perovskites.

As DFT calculations are performed at temperatures close to absolute zero, the conductivity map in Figure 7 holds only at that particular condition. For most of the catalysts, the conductivity is constant with temperature, however for $\mathrm{Co}^{3+}$, the conductivity is temperature dependent because the non-conductive $\mathrm{Co}^{3+}(\mathrm{LS})$ is thermally excited to conductive $\mathrm{Co}^{3+}$ (IS). Therefore, we believe that most of catalysts with host or dopant $\mathrm{Co}^{3+}$ will be electronically conductive at room temperatures. As stated in the introduction, we consider only bulk catalysts here, wherein the conductivity is dependent on the size of the band gap and the concentration of charge carriers. It should, however, be noted that surfaces of bulk insulating materials can be conductive owing to different oxidation states of surface ions in comparison to bulk.

We find that approximately half of the catalysts are semiconductors and half support some kind of electronic conduction. The purpose of this work is to show whether charge transport is possible and not to quantify the charge carrier mobility. From oxides that are electronically conductive, we distinguish three different conductivity types: intrinsic conductivity (I), charge transport via electron polarons $(\mathrm{P})^{103}$ and charge transport via holes $(\mathrm{H})$ in the valence band, where holes can either be in the metal $3 d$ or O $2 p$ states. We illustrate the different charge transfer types by three representative examples. 


\begin{tabular}{|c|c|c|c|c|c|}
\hline $\mathrm{LaCrO}_{3}$ & $\mathrm{LaMnO}_{3}$ & $\mathrm{LaFeO}_{3}$ & $\mathrm{LaCoO}_{3}$ & $\mathrm{LaNiO}_{3}$ & $\mathrm{LaCuO}_{3}$ \\
\hline no & no & no & no & I & $H(2 p)$ \\
\hline $\mathrm{Mn}$ & no & no & no & I & $H(2 p)$ \\
\hline no & no & no & no & 1 & no \\
\hline no & no & no & no & I & no \\
\hline $\mathrm{IH}$ & no & no & IH & I & 1 \\
\hline no & $P$ & no & no & I & no \\
\hline no & $P$ & $H(2 p)$ & $\mathrm{IH}$ & 1 & $H(3 d)$ \\
\hline$H(2 p)$ & $P$ & $H(2 p)$ & $\mathrm{IH}$ & I & $H(3 d)$ \\
\hline$H(2 p)$ & $P$ & $H(2 p)$ & IH & I & $H(3 d)$ \\
\hline
\end{tabular}

Figure 7 Conductivity map for doped La perovskite oxides. Conduction type (I-intrinsic, P-polaron and H-hole transport via $\mathrm{O} 2 \mathrm{p}$ or metal $3 d$ states denoted in brackets) is shown for electrically conductive catalysts at absolute zero.

For type I, charge transport originates from the strong overlap between the metal $e_{g}$ and O $2 p$ orbitals resulting in a broad hybridized state that straddles the Fermi level. This is a characteristic of $\mathrm{Ni}^{3+}$ and $\mathrm{Co}^{3+}$ (IS) ions (cf. $\mathrm{LaNiO}_{3}$ in Figure 8). For type $\mathrm{P}$, charge transfer takes place via electron hopping between $\mathrm{Mn}^{3+} / \mathrm{Mn}^{4+}\left(\mathrm{LaMnO}_{3}\right.$ doped with alkaline-earth metals or $\mathrm{Cu}$ ) ion pairs. The electronic conduction is triggered by a magnetic double exchange, which allows electron hopping from $\mathrm{Mn}^{3+}$ to neighboring $\mathrm{Mn}^{4+}$ ions through intermediary oxygen. As seen in Figure $7, \mathrm{H}$ is the dominant conduction type that corresponds to the p-type doping and most times occurs when a host metal is replaced by an element with a lower valence. There are two different kinds of holes depending on the position of the metal $3 d$ and $\mathrm{O} 2 p$ states. In the case of alkaline-earth doped $\mathrm{LaFeO}_{3}(\mathrm{cf}$. Figure 8) holes are centred on oxygen ligands and in the case of alkaline-earth doped $\mathrm{LaCuO}_{3}$ they are delocalized over $\mathrm{Cu}$ ions (see Note 3 and 4 in ESI). The delocalization is explained in more details in the following. 


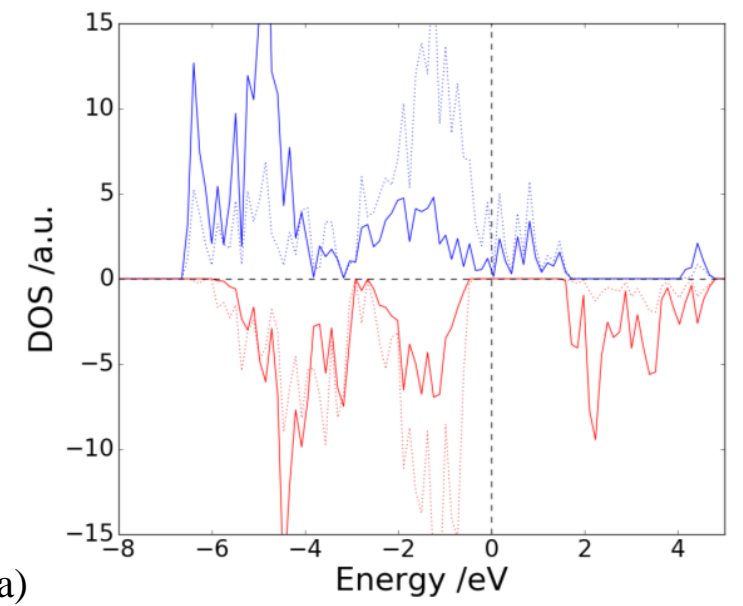

a)

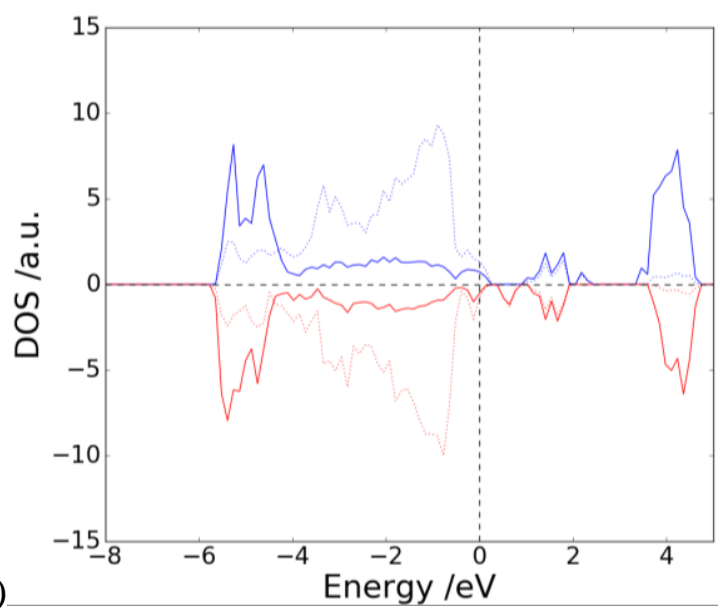

b)

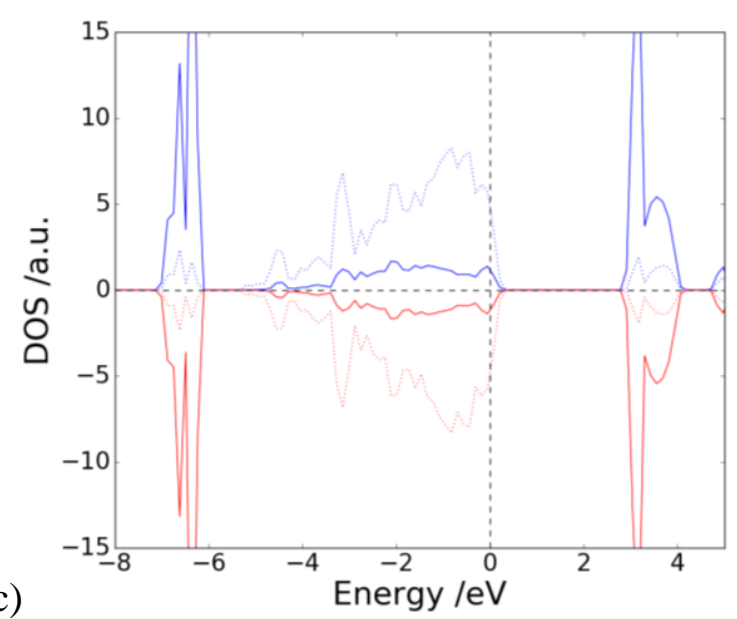

Figure 8 Three representative cases of different electron conduction types a) $\mathrm{LaNiO}_{3}$ (I) b) $\mathrm{LaCa}_{0.25} \mathrm{Mn}_{0.75} \mathrm{O}_{3}(\mathrm{P})$ and c) $\mathrm{LaCa}_{0.25} \mathrm{Fe}_{0.75} \mathrm{O}_{3}(\mathrm{H})$. Solid and dashed lines are density of states projected onto metal $3 d$ and oxygen $2 p$ levels, respectively.

In a simple Zaanen, Sawatzky and Allan (ZSA) framework, ${ }^{104}$ the separation into charge transfer and Mott-Hubbard insulators is made contingent on which of the two states comprise the valence band. In reality, the hybridized states at the Fermi level have both the 
O $2 p$ and metal $3 d$ character; therefore, strictly speaking, there are many intermediate cases in-between the two limiting. If the valence band is dominated by the $\mathrm{O} 2 p$ states, upon partial substitution with a lower valent element, the dopant atom draws charge from the $\mathrm{O}$ $2 p$ states. Otherwise, if host $3 d$ states dominate the valence band, electrons are drawn from the $3 d$ levels of host $\mathrm{B}$ cations. An example of the former case is $\mathrm{La}_{0.75} \mathrm{Ca}_{0.25} \mathrm{FeO}_{3}$ in which Ca substitution for La takes an electron from the $\mathrm{O} 2 p$ states giving rise to a delocalized ligand-hole $(L)$. An example of the latter case is $\mathrm{La}_{0.75} \mathrm{Ca}_{0.25} \mathrm{MnO}_{3}$, where an electron is taken from $\mathrm{Mn}^{3+}$ to make $\mathrm{Mn}^{4+}$. A particularly intriguing case is doped $\mathrm{LaCuO}_{3}$. If doped by an element that prefers the +4 state, such as $\mathrm{Mn}$ or $\mathrm{Cr}$, the excess electron is delocalized over vicinal oxygens ions. On the other hand, if doped with an alkaline earth element at A site, the electron is withdrawn from the $\mathrm{Cu} 3 d$ levels. In certain cases, the interaction of two different types can be the origin of electronic conductance. Such examples are Ni doped $\mathrm{LaCrO}_{3}$ or $\mathrm{LaCoO}_{3}$, wherein the $\mathrm{Ni}$ oxidation state is in between +2 and +3 . $\mathrm{Ni}^{+(2-3)}$ hybridizes with nearby $L$ created by partial charge transfer to $\mathrm{Ni}^{+3}$. All compounds with $\mathrm{Ni}$ are in general conductors, with type I dominating through $\mathrm{Ni}^{3+}$, except for $\mathrm{LaFe}_{0.75} \mathrm{Ni}_{0.25} \mathrm{O}_{3}$ and $\mathrm{LaMn}_{0.75} \mathrm{Ni}_{0.25} \mathrm{O}_{3}$. In $\mathrm{LaFe}_{0.75} \mathrm{Ni}_{0.25} \mathrm{O}_{3}, \mathrm{Ni}$ is $\mathrm{Ni}^{3+}$, but the band-gap is so large that the presence of $\mathrm{Ni}^{3+}$ does not really have an effect on the conductance. The non-conductive $\mathrm{Ni}^{3+}$ is supported by presence of JT distortions. In $\mathrm{LaMn}_{0.75} \mathrm{Ni}_{0.25} \mathrm{O}_{3}$, Ni becomes non-conductive $\mathrm{Ni}^{2+}$, followed by oxidation of host $\mathrm{Mn}^{3+}$ to $\mathrm{Mn}^{4+}$. We do not observe polarons in $\mathrm{LaMn}_{0.75} \mathrm{Ni}_{0.25} \mathrm{O}_{3}$ despite having mixed $\mathrm{Mn}$ valences.

\section{Conclusions}

In summary, we have investigated the performance of the selected pure and doped perovskite oxides for the OER using two commonly employed computational approaches, DFT+U and HSE. We arrive at following conclusions:

1. The U-parameter in DFT+U and the $\alpha$-parameter in HSE calculations have huge effects on the calculated heats of formation in cases where the B cation valence is different in the perovskite and the reference oxide from which it is calculated. We find that crystal structures with faceshared octahedra are the most stable catalysts and those with negative charge transfer energy are the least stable catalysts. 
2. During a full oxidation cycle, the surface metal B cation changes its oxidation state depending on reaction intermediate and $B$ cation type. We find a large influence on the choice of $U$ and $\alpha$ values on the calculated adsorption energies and reaction overpotentials derived from these. This finding makes it challenging to rate and compare activities across a broad range of different perovskite oxide electrocatalysts.

3. HSE calculations cannot be used as benchmarks for evaluating the stability and activity of perovskite oxides, since the results are as sensitive on the choice of $\alpha$ as they are on the choice of U. In fact, we see little benefit in using HSE-level calculations for studying multi-step electrochemical reactions on complex oxides, which does not seem to warrant the excess computational cost.

4. The electronic conductivity is found to be less sensitive to the specific choice of $U$ or $\alpha$. Here, we distinguish among three different conduction types: intrinsic conduction for $\mathrm{Fe}^{4+}, \mathrm{Co}^{3+}$ (IS) and $\mathrm{Ni}^{3+}$ originating from partial occupancy of the $\mathrm{e}_{\mathrm{g}}$ orbital, electron polaron hopping along the $\mathrm{Mn}^{3+}-\mathrm{O}-\mathrm{Mn}^{4+}$ chains and conductance via oxygen $2 p$ or metal $3 d$ holes in the valence band.

\section{Supporting Information}

Supporting Information contains 4 Notes:

Note 1: Pertinent surface termination of pure perovskite oxides

Note 2: Tables with free energy values for steps 1-10.

Note 3: Density of states plots for doped La perovskites.

Note 4: Magnetic moments of doped La perovskites

\section{Contact information}

Corresponding author:

Vladimir Tripkovic, email: tripce@gmail.com

Mailing address: Department of Energy Conversion and Storage, Technical University of Denmark, Fysikvej - building 309, 2800 Lyngby, Denmark. 


\section{Acknowledgements}

This work was supported by the Horizon 2020 framework project ZAS, grant number 646186. We would also like to acknowledge the Velux Foundations for support through The VILLUM Center for the Science of Sustainable Fuels and Chemicals (grant number 9455).

\section{References}

(1) Ishihara, T.; Matsuda, H.; Takita, Y. Doped L a G a 03 Perovskite Type Oxide as a New Oxide Ionic Conductor. J. Am. Chem. Soc 1994, 116, 3801-3803.

(2) Li, M.; Pietrowski, M. J.; De Souza, R. A.; Zhang, H.; Reaney, I. M.; Cook, S. N.; Kilner, J. A.; Sinclair, D. C. A Family of Oxide Ion Conductors Based on the Ferroelectric Perovskite Na0.5Bi0.5TiO3. Nat. Mater. 2013, 13 (1), 31-35.

(3) Skinner, S. J.; Kilner, J. A. Oxygen Ion Conductors. Mater. Today 2003, 6 (3), 30-37.

(4) Tokura, Y.; Kobayashi, K.-I.; Kimura, T.; Sawada, H.; Terakura, K. Room-Temperature Magnetoresistance in an Oxide Material with an Ordered Double-Perovskite Structure. Nature 1998, 395 (6703), 677-680.

(5) Rao, C. N. R.; Raveau, B. Colossal Magnetoresistance, Charge Ordering and Related Properties of Manganese Oxides; WORLD SCIENTIFIC, 1998.

(6) Reyren, N.; Thiel, S.; Caviglia, A. D.; Kourkoutis, L. F.; Hammerl, G.; Richter, C.; Schneider, C. W.; Kopp, T.; Rüetschi, A.-S.; Jaccard, D.; et al. Superconducting Interfaces Between Insulating Oxides. Science (80-. ). 2007, 317 (5842).

(7) Cava, R. J.; Batlogg, B.; van Dover, R. B.; Murphy, D. W.; Sunshine, S.; Siegrist, T.; Remeika, J. P.; Rietman, E. A.; Zahurak, S.; Espinosa, G. P. Bulk Superconductivity at $91 \mathrm{~K}$

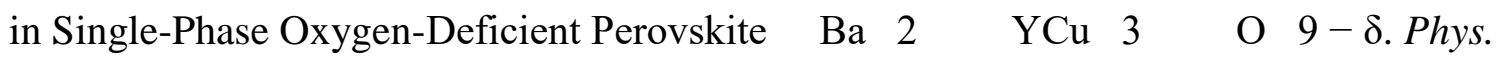
Rev. Lett. 1987, 58 (16), 1676-1679.

(8) Peña, M. A.; Fierro, J. L. G. Chemical Structures and Performance of Perovskite Oxides. Chemical Reviews. American Chemical Society 2001, pp 1981-2017.

(9) Arakawa, T.; Kurachi, H.; Shiokawa, J. Physicochemical Properties of Rare Earth Perovskite Oxides Used as Gas Sensor Material. J. Mater. Sci. 1985, 20 (4), 1207-1210. 
(10) Suntivich, J.; Gasteiger, H. A.; Yabuuchi, N.; Nakanishi, H.; Goodenough, J. B.; Shao-Horn, Y. Design Principles for Oxygen-Reduction Activity on Perovskite Oxide Catalysts for Fuel Cells and Metal-Air Batteries. Nat. Chem. 2011, 3 (7), 546-550.

(11) Cheng, F.; Chen, J. Metal-Air Batteries: From Oxygen Reduction Electrochemistry to Cathode Catalysts. Chem. Soc. Rev. 2012, 41 (6), 2172-2192.

(12) Suntivich, J.; May, K. J.; Gasteiger, H. A.; Goodenough, J. B.; Shao-Horn, Y. A Perovskite Oxide Optimized for Oxygen Evolution Catalysis from Molecular Orbital Principles. Science (80-. ). 2011, 334 (6061), 1383-1385.

(13) Grimaud, A.; May, K. J.; Carlton, C. E.; Lee, Y.-L.; Risch, M.; Hong, W. T.; Zhou, J.; ShaoHorn, Y. Double Perovskites as a Family of Highly Active Catalysts for Oxygen Evolution in Alkaline Solution. Nat. Commun. 2013, 4, 2439.

(14) Han, B.; Risch, M.; Lee, Y.-L.; Ling, C.; Jia, H.; Shao-Horn, Y. Activity and Stability Trends of Perovskite Oxides for Oxygen Evolution Catalysis at Neutral pH. Phys. Chem. Chem. Phys. 2015, 17 (35), 22576-22580.

(15) Hong, W. T.; Stoerzinger, K. A.; Lee, Y.-L.; Giordano, L.; Grimaud, A.; Johnson, A. M.; Hwang, J.; Crumlin, E. J.; Yang, W.; Shao-Horn, Y. Charge-Transfer-Energy-Dependent Oxygen Evolution Reaction Mechanisms for Perovskite Oxides. Energy Environ. Sci. 2017, 10 (10), 2190-2200.

(16) Vojvodic, A.; Nørskov, J. K. Chemistry. Optimizing Perovskites for the Water-Splitting Reaction. Science 2011, 334 (6061), 1355-1356.

(17) Man, I. C.; Su, H.-Y.; Calle-Vallejo, F.; Hansen, H. A.; Martínez, J. I.; Inoglu, N. G.; Kitchin, J.; Jaramillo, T. F.; Nørskov, J. K.; Rossmeisl, J. Universality in Oxygen Evolution Electrocatalysis on Oxide Surfaces. ChemCatChem 2011, 3 (7), 1159-1165.

(18) Hong, W. T.; Welsch, R. E.; Shao-Horn, Y. Descriptors of Oxygen-Evolution Activity for Oxides: A Statistical Evaluation. J. Phys. Chem. C 2016, 120 (1), 78-86.

(19) Bhattacharya, A.; May, S. J.; Te Velthuis, S. G. E.; Warusawithana, M.; Zhai, X.; Shah, A. B.; Zuo, J.-M.; Fitzsimmons, M. R.; Bader, S. D.; Eckstein, J. N. The Metal-Insulator Transition and Its Relation to Magnetic Structure in (LaMnO 3 ) 2n /(SrMnO 3 ) N 
Superlattices. Phys. Rev. Lett. 2008, 100 (25).

(20) Jilili, J.; Cossu, F.; Schwingenschlögl, U. Trends in (LaMnO3)n/(SrTiO3)m Superlattices with Varying Layer Thicknesses. Sci. Rep. 2015, 5, 13762.

(21) Stoerzinger, K. A.; Choi, W. S.; Jeen, H.; Lee, H. N.; Shao-Horn, Y. Role of Strain and Conductivity in Oxygen Electrocatalysis on $\mathrm{LaCoO}_{3}$ Thin Films. J. Phys. Chem. Lett. 2015, $6(3), 487-492$.

(22) Goldschmidt, V. M.; M., V. Die Gesetze Der Krystallochemie. Naturwissenschaften 1926, 14 (21), 477-485.

(23) Kresse, G.; Furthmüller, J. Efficient Iterative Schemes for Ab Initio Total-Energy Calculations Using a Plane-Wave Basis Set. Phys. Rev. B 1996, 54 (16), 11169-11186.

(24) Perdew, J. P.; Burke, K.; Ernzerhof, M. Generalized Gradient Approximation Made Simple. Phys. Rev. Lett. 1996, 77 (18), 3865-3868.

(25) Dudarev, S. L.; Botton, G. A.; Savrasov, S. Y.; Humphreys, C. J.; Sutton, A. P. ElectronEnergy-Loss Spectra and the Structural Stability of Nickel Oxide: An LSDA+U Study. Phys. Rev. B 1998, 57 (3), 1505-1509.

(26) Heyd, J.; Scuseria, G. E.; Ernzerhof, M. Hybrid Functionals Based on a Screened Coulomb Potential. J. Chem. Phys. 2003, 118 (18), 8207-8215.

(27) He, J.; Franchini, C. Screened Hybrid Functional Applied to $3 d^{\wedge} 0--\& g t ; 3 d^{\wedge} 8$ TransitionMetal Perovskites LaMO3 (M=Sc-Cu): Influence of the Exchange Mixing Parameter on the Structural, Electronic and Magnetic Properties. Phys. Rev. B, vol. 86, Issue 23, id. 235117 2012, 86 (23).

(28) Lee, Y.-L.; Gadre, M. J.; Shao-Horn, Y.; Morgan, D. Ab Initio GGA+U Study of Oxygen Evolution and Oxygen Reduction Electrocatalysis on the (001) Surfaces of Lanthanum Transition Metal Perovskites $\mathrm{LaBO}_{3}(\mathrm{~B}=\mathrm{Cr}, \mathrm{Mn}, \mathrm{Fe}, \mathrm{Co}$ and Ni). Phys. Chem. Chem. Phys. 2015, 17 (33), 21643-21663.

(29) Pourbaix, M. Atlas of Electrochemical Equilibria in Aqueous Solutions, Second.; National Association of Corrosion Engineers: Houston, Texas, 1974. 
(30) Haupt, S.; Strehblow, H. H. Corrosion, Layer Formation, and Oxide Reduction of Passive Iron in Alkaline Solution: A Combined Electrochemical and Surface Analytical Study. Langmuir 1987, 3 (6), 873-885.

(31) Blöchl, P. E. First-Principles Calculations of Defects in Oxygen-Deficient Silica Exposed to Hydrogen. Phys. Rev. B 2000, 62 (10), 6158-6179.

(32) Nørskov, J. K.; Rossmeisl, J.; Logadottir, A.; Lindqvist, L.; Kitchin, J. R.; Bligaard, T.; Jonsson, H. Origin of the Overpotential for Oxygen Reduction at a Fuel-Cell Cathode. $J$. Phys. Chem. B 2004, 108 (46), 17886-17892.

(33) Rossmeisl, J.; Qu, Z. W.; Zhu, H.; Kroes, G. J.; Nørskov, J. K. Electrolysis of Water on Oxide Surfaces. J. Electroanal. Chem. 2007, 607 (1-2), 83-89.

(34) López, R.; Gómez, R. Band-Gap Energy Estimation from Diffuse Reflectance Measurements on Sol-gel and Commercial TiO2: A Comparative Study. J. Sol-Gel Sci. Technol. 2012, 61 (1), 1-7.

(35) Arima, T.; Tokura, Y.; Torrance, J. B. Variation of Optical Gaps in Perovskite-Type 3 D Transition-Metal Oxides. Phys. Rev. B 1993, 48 (23), 17006-17009.

(36) Adkin, J. J.; Hayward, M. A. BaMnO3-X Revisited: A Structural and Magnetic Study. Chem. Mater. 2007, 19 (4), 755-762.

(37) Lacorre, P.; Torrance, J. B.; Pannetier, J.; Nazzal, A. I.; Wang, P. W.; Huang, T. C. Synthesis, Crystal Structure, and Properties of Metallic PrNiO3: Comparison with Metallic NdNiO3 and Semiconducting SmNiO3. J. Solid State Chem. 1991, 91 (2), 225-237.

(38) Darriet, J.; Subramanian, M. A. Structural Relationships between Compounds Based on the Stacking of Mixed Layers Related to Hexagonal Perovskite-Type Structures. J. Mater. Chem. 1995, 5 (4), 543.

(39) Korotin, M. A.; Ezhov, S. Y.; Solovyev, I. V.; Anisimov, V. I.; Khomskii, D. I.; Sawatzky, G. A. Intermediate-Spin State and Properties of $\mathrm{LaCoO}$ 3. Phys. Rev. B 1996, 54 (8), 5309-5316.

(40) Potze, R. H.; Sawatzky, G. A.; Abbate, M. Possibility for an Intermediate-Spin Ground State 
in the Charge-Transfer Material SrCoO 3. Phys. Rev. B 1995, 51 (17), 11501-11506.

(41) Yano, H.; Inukai, J.; Uchida, H.; Watanabe, M.; Babu, P. K.; Kobayashi, T.; Chung, J. H.; Oldfield, E.; Wieckowski, A. Particle-Size Effect of Nanoscale Platinum Catalysts in Oxygen Reduction Reaction: An Electrochemical and 195Pt EC-NMR Study. Phys. Chem. Chem. Phys. 2006, 8 (42), 4932-4939.

(42) Kwon, J.-H.; Choi, W. S.; Kwon, Y.-K.; Jung, R.; Zuo, J.-M.; Lee, H. N.; Kim, M. Nanoscale Spin-State Ordering in $\mathrm{LaCoO}_{3}$ Epitaxial Thin Films. Chem. Mater. 2014, 26 (8), 2496-2501.

(43) Hashimoto, T.; Tsuzuki, N.; Kishi, A.; Takagi, K.; Tsuda, K.; Tanaka, M.; Oikawa, K.; Kamiyama, T.; Yoshida, K.; Tagawa, H.; et al. Analysis of Crystal Structure and Phase Transition of LaCrO3 by Various Diffraction Measurements. Solid State Ionics 2000, 132 (3), 181-188.

(44) Zhou, J.-S.; Alonso, J. A.; Muoñz, A.; Fernández-Díaz, M. T.; Goodenough, J. B. Magnetic Structure of LaCrO 3 Perovskite under High Pressure from In Situ Neutron Diffraction. Phys. Rev. Lett. 2011, 106 (5), 57201.

(45) Norby, P.; Andersen, I. G. K.; Andersen, E. K.; Andersen, N. H. The Crystal Structure of Lanthanum Manganate(iii), LaMnO3, at Room Temperature and at $1273 \mathrm{~K}$ under N2. $J$. Solid State Chem. 1995, 119 (1), 191-196.

(46) Nohara, Y.; Yamasaki, A.; Kobayashi, S.; Fujiwara, T. Electronic Structure of A-Type Antiferomagnetic LaMnO_3 by GW Approximation. Phys. Rev. B 2006, 74 (6).

(47) Marezio, M.; Dernier, P. D. The Bond Lengths in LaFeO3. Mater. Res. Bull. 1971, 6 (1), 2329.

(48) Ravindran, P.; Vidya, R.; Fjellvåg, H.; Kjekshus, A. Electronic Structure and Excited-State Properties of Perovskite-like Oxides. J. Cryst. Growth 2004, 268 (3), 554-559.

(49) Kobayashi, Y.; Mitsunaga, T.; Fujinawa, G.; Arii, T.; Suetake, M.; Asai, K.; Harada, J. Structural Phase Transition from Rhombohedral to Cubic in $\mathrm{LaCoO}$ 3. J. Phys. Soc. Japan 2000, 69 (10), 3468-3469. 
(50) Radaelli, P. G.; Cheong, S.-W. Structural Phenomena Associated with the Spin-State Transition in LaCoO 3. Phys. Rev. B 2002, 66 (9), 94408.

(51) Hamada, N. Electronic Band Structure of LaNiO3. J. Phys. Chem. Solids 1993, 54 (10), $1157-1160$.

(52) García-Muñoz, J. L.; Rodríguez-Carvajal, J.; Lacorre, P.; Torrance, J. B. Neutron-Diffraction Study of $R \quad \mathrm{NiO} \quad 3 \quad(R=\mathrm{La}, \mathrm{Pr}, \mathrm{Nd}, \mathrm{Sm})$ : Electronically Induced Structural Changes across the Metal-Insulator Transition. Phys. Rev. B 1992, 46 (8), 4414-4425.

(53) Medarde, M. L. Structural, Magnetic and Electronic Properties of Perovskites (R = Rare Earth). J. Phys. Condens. Matter 1997, 9 (8), 1679-1707.

(54) Czyżyk, M. T.; Sawatzky, G. A. Local-Density Functional and on-Site Correlations: The Electronic Structure of $\mathrm{La} 2 \mathrm{CuO} 4$ and LaCuO 3. Phys. Rev. B 1994, 49 (20), 14211-14228.

(55) Mizokawa, T.; Fujimori, A.; Namatame, H.; Takeda, Y.; Takano, M. Electronic Structure of Tetragonal LaCuO 3 Studied by Photoemission and X-Ray-Absorption Spectroscopy. Phys. Rev. B 1998, 57 (16), 9550-9556.

(56) Bringley, J. F.; Scott, B. A.; La Placa, S. J.; McGuire, T. R.; Mehran, F.; McElfresh, M. W.; Cox, D. E. Structure and Properties of the $\mathrm{LaCuO} 3-\delta \quad$ Perovskites. Phys. Rev. B 1993, 47 (22), 15269-15275.

(57) Komarek, A. C.; Streltsov, S. V.; Isobe, M.; Möller, T.; Hoelzel, M.; Senyshyn, A.; Trots, D.; Fernández-Díaz, M. T.; Hansen, T.; Gotou, H.; et al. CaCrO 3 : An Anomalous Antiferromagnetic Metallic Oxide. Phys. Rev. Lett. 2008, 101 (16), 167204.

(58) Molinari, M.; Tompsett, D. A.; Parker, S. C.; Azough, F.; Freer, R. Structural, Electronic and

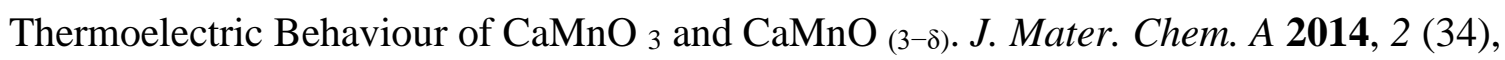
14109-14117.

(59) Poeppelmeier, K. R.; Leonowicz, M. E.; Scanlon, J. C.; Longo, J. M.; Yelon, W. B. Structure Determination of $\mathrm{CaMnO} 3$ and $\mathrm{CaMnO} 2.5$ by X-Ray and Neutron Methods. J. Solid State Chem. 1982, 45 (1), 71-79. 
(60) Wiebe, C. R.; Greedan, J. E.; Gardner, J. S.; Zeng, Z.; Greenblatt, M. Charge and Magnetic Ordering in the Electron-Doped Magnetoresistive Materials $\mathrm{CaMnO} 3-\delta \quad(\delta=0.06$, 0.11 ). Phys. Rev. B 2001, 64 (6), 64421.

(61) Woodward, P. M.; Cox, D. E.; Moshopoulou, E.; Sleight, A. W.; Morimoto, S. Structural Studies of Charge Disproportionation and Magnetic Order in CaFeO 3. Phys. Rev. B 2000, 62 (2), 844-855.

(62) Long, Y.; Kaneko, Y.; Ishiwata, S.; Taguchi, Y.; Tokura, Y. Synthesis of Cubic $\mathrm{SrCoO}_{3}$ Single Crystal and Its Anisotropic Magnetic and Transport Properties. J. Phys. Condens. Matter 2011, 23 (24), 245601.

(63) Ortega-San-Martin, L.; Williams, A. J.; Rodgers, J.; Attfield, J. P.; Heymann, G.; Huppertz, H. Microstrain Sensitivity of Orbital and Electronic Phase Separation in SrCrO 3. Phys. Rev. Lett. 2007, 99 (25), 255701.

(64) Søndenå, R.; Ravindran, P.; Stølen, S.; Grande, T.; Hanfland, M. Electronic Structure and Magnetic Properties of Cubic and Hexagonal Sr Mn O 3. Phys. Rev. B 2006, 74 (14), 144102.

(65) Bocquet, A. E.; Fujimori, A.; Mizokawa, T.; Saitoh, T.; Namatame, H.; Suga, S.; Kimizuka, N.; Takeda, Y.; Takano, M. Electronic Structure of SrFe 4 + O 3 and Related Fe Perovskite Oxides. Phys. Rev. B 1992, 45 (4), 1561-1570.

(66) Takeda, T.; Yamaguchi, Y.; Watanabe, H. Magnetic Structure of $\mathrm{SrFeO}$ 3. J. Phys. Soc. Japan 1972, 33 (4), 967-969.

(67) Bezdicka, P.; Wattiaux, A.; Grenier, J. C.; Pouchard, M.; Hagenmuller, P. Preparation and Characterization of Fully Stoichiometric SrCoO3 by Electrochemical Oxidation. Zeitschrift for Anorg. und Allg. Chemie 1993, 619 (1), 7-12.

(68) Zhu, Z. H.; Rueckert, F. J.; Budnick, J. I.; Hines, W. A.; Jain, M.; Zhang, H.; Wells, B. O. Magnetic and Electronic Structure of the Film-Stabilized Mott Insulator BaCrO 3. Phys. Rev. B 2013, 87 (19), 195129.

(69) Chamberland, B. L.; Sleight, A. W.; Weiher, J. F. Preparation and Characterization of BaMnO3 and SrMnO3 Polytypes. J. Solid State Chem. 1970, 1 (3-4), 506-511. 
(70) Li, Z.; Iitaka, T.; Tohyama, T. Pressure Induced Ferromagnetism in Cubic Perovskite SrFeO. Phys. Rev. B 2012, 86 (9).

(71) Hayashi, N.; Yamamoto, T.; Kageyama, H.; Nishi, M.; Watanabe, Y.; Kawakami, T.; Matsushita, Y.; Fujimori, A.; Takano, M. BaFeO3: A Ferromagnetic Iron Oxide. Angew. Chemie Int. Ed. 2011, 50 (52), 12547-12550.

(72) Pardo, V.; Blaha, P.; Iglesias, M.; Schwarz, K.; Baldomir, D.; Arias, J. E. Magnetic Structure and Orbital Ordering in BaCoO 3 from First-Principles Calculations. Phys. Rev. B 2004, 70 (14).

(73) Felser, C.; Yamaura, K.; Cava, R. J. The Electronic Structure of Hexagonal BaCoO3. J. Solid State Chem. 1999, 146 (2), 411-417.

(74) Takeda, Y. Magnetic Property in the System BaCo1-xNixO3 $(\mathrm{X}=0 \sim 1)$. J. Solid State Chem. 1975, 15 (1), 40-44.

(75) Takeda, Y.; Kanamura, F.; Shimada, M.; Koizumi, M.; IUCr. The Crystal Structure of BaNiO3. Acta Crystallogr. Sect. B Struct. Crystallogr. Cryst. Chem. 1976, 32 (8), 24642466.

(76) Suntivich, J.; May, K. J.; Gasteiger, H. A.; Goodenough, J. B.; Shao-Horn, Y. A Perovskite Oxide Optimized for Oxygen Evolution Catalysis from Molecular Orbital Principles. Science (80-. ). 2011, 334 (6061), 1383-1385.

(77) Loa, I.; Adler, P.; Grzechnik, A.; Syassen, K.; Schwarz, U.; Hanfland, M.; Rozenberg, G. K.; Gorodetsky, P.; Pasternak, M. P. Pressure-Induced Quenching of the Jahn-Teller Distortion and Insulator-to-Metal Transition in LaMnO 3. Phys. Rev. Lett. 2001, 87 (12), 125501.

(78) Heaton, R. A.; Harrison, J. G.; Lin, C. C. Self-Interaction Correction for Density-Functional Theory of Electronic Energy Bands of Solids. Phys. Rev. B 1983, 28 (10), 5992-6007.

(79) Loschen, C.; Carrasco, J.; Neyman, K. M.; Illas, F. First-Principles LDA + U and GGA + U Study of Cerium Oxides: Dependence on the Effective U Parameter. Phys. Rev. B 2007, 75 (3), 35115.

(80) Capdevila-Cortada, M.; Łodziana, Z.; López, N. Performance of DFT $+U$ Approaches in the 
Study of Catalytic Materials. ACS Catal. 2016, 6 (12), 8370-8379.

(81) Yin, W.-G.; Volja, D.; Ku, W. Orbital Ordering in LaMnO 3 : Electron-Electron versus Electron-Lattice Interactions. Phys. Rev. Lett. 2006, 96 (11), 116405.

(82) Mellan, T. A.; Cora, F.; Grau-Crespo, R.; Ismail-Beigi, S. The Importance of Anisotropic Coulomb Interaction in LaMnO 3. Phys. Rev. B 2015, 92 (8).

(83) Yang, Z.; Huang, Z.; Ye, L.; Xie, X. Influence of Parameters U and J in the LSDA \%U Method on Electronic Structure of the Perovskites LaMO 3 \&quot; M,Cr,Mn,Fe,Co,Ni.... Phys. Rev. 1999, 60 (23), 15674-15682.

(84) Nohara, Y.; Yamamoto, S.; Fujiwara, T. Electronic Structure of Perovskite-Type Transition Metal Oxides $\mathrm{LaM} \mathrm{O} 3 \quad(\mathrm{M}=\mathrm{Ti} \sim \mathrm{Cu})$ by $\mathrm{U}+\mathrm{GW}$ Approximation. Phys. Rev. B 2009, 79 (19), 195110.

(85) Skone, J. H.; Govoni, M.; Galli, G. Self-Consistent Hybrid Functional for Condensed Systems. Phys. Rev. B 2014, 89 (19), 195112.

(86) McLean, G. An Assessment of Alkaline Fuel Cell Technology. Int. J. Hydrogen Energy 2002, 27 (5), 507-526.

(87) Sapkota, P.; Kim, H. Zinc-air Fuel Cell, a Potential Candidate for Alternative Energy. J. Ind. Eng. Chem. 2009, 15 (4), 445-450.

(88) Bidault, F.; Brett, D. J. L.; Middleton, P. H.; Brandon, N. P. Review of Gas Diffusion Cathodes for Alkaline Fuel Cells. J. Power Sources 2009, 187 (1), 39-48.

(89) Zhou, J.-S.; Jin, C.-Q.; Long, Y.-W.; Yang, L.-X.; Goodenough, J. B. Anomalous Electronic State in $\mathrm{CaCrO} 3$ and SrCrO 3. Phys. Rev. Lett. 2006, 96 (4), 46408.

(90) Kanamaru, F.; Miyamoto, H.; Mimura, Y.; Koizumi, M.; Shimada, M.; Kume, S.; Shin, S. Synthesis of a New Perovskite CaFeO3. Mater. Res. Bull. 1970, 5 (4), 257-261.

(91) Grimaud, A.; Diaz-Morales, O.; Han, B.; Hong, W. T.; Lee, Y.-L.; Giordano, L.; Stoerzinger, K. A.; Koper, M. T. M.; Shao-Horn, Y. Activating Lattice Oxygen Redox Reactions in Metal Oxides to Catalyse Oxygen Evolution. Nat. Chem. 2017, 9 (5), 457-465. 
(92) Daniel I. Khomskii. Transition Metal Oxides; Cambridge University Press, 2014.

(93) Chen, W.-T.; Saito, T.; Hayashi, N.; Takano, M.; Shimakawa, Y. Ligand-Hole Localization in Oxides with Unusual Valence Fe. Sci. Rep. 2012, 2, 210-213.

(94) Matsuno, J.; Mizokawa, T.; Fujimori, A.; Takeda, Y.; Kawasaki, S.; Takano, M. Different Routes to Charge Disproportionation in Perovskite-Type Fe Oxides. Phys. Rev. B 2002, 66 (19), 193103.

(95) Johnston, S.; Mukherjee, A.; Elfimov, I.; Berciu, M.; Sawatzky, G. A. Charge Disproportionation without Charge Transfer in the Rare-Earth-Element Nickelates as a Possible Mechanism for the Metal-Insulator Transition. Phys. Rev. Lett. 2014, 112 (10), 106404.

(96) Matsumoto, Y.; Sato, E. ELECTROCATALYTIC PROPERTIES OF TRANSITION METAL OXIDES FOR OXYGEN EVOLUTION REACTION. Mater. Chem. Phys. 1986, 4, $397-426$.

(97) Hong, D.; Yamada, Y.; Nagatomi, T.; Takai, Y.; Fukuzumi, S. Catalysis of Nickel Ferrite for Photocatalytic Water Oxidation Using $\left[\mathrm{Ru}(\mathrm{bpy})_{3}\right]^{2+}$ and $\mathrm{S}_{2} \mathrm{O}_{8}{ }^{2-}$. J. Am. Chem. Soc. 2012, 134 (48), 19572-19575.

(98) Hoffmann, M.; Borisov, V. S.; Ostanin, S.; Mertig, I.; Hergert, W.; Ernst, A. Magnetic Properties of Defect-Free and Oxygen-Deficient Cubic SrCoO 3- . Phys. Rev. B 2015, 92 (9).

(99) Zhou, F.; Cococcioni, M.; Marianetti, C. A.; Morgan, D.; Ceder, G. First-Principles Prediction of Redox Potentials in Transition-Metal Compounds with LDA + U. Phys. Rev. B 2004, 70 (23), 235121.

(100) Yagi, S.; Yamada, I.; Tsukasaki, H.; Seno, A.; Murakami, M.; Fujii, H.; Chen, H.; Umezawa, N.; Abe, H.; Nishiyama, N.; et al. Covalency-Reinforced Oxygen Evolution Reaction Catalyst. Nat. Commun. 2015, 6, 8249.

(101) Xu, Z.; Rossmeisl, J.; Kitchin, J. R. A Linear Response DFT+ U Study of Trends in the Oxygen Evolution Activity of Transition Metal Rutile Dioxides. J. Phys. Chem. C 2015, 119 (9), 4827-4833. 
(102) Loftager, S.; García-Fernández, P.; Aramburu, J. A.; Moreno, M.; Garcia-Lastra, J. M. Stability and Polaronic Motion of Self-Trapped Holes in Silver Halides: Insight through DFT+ U Calculations. J. Phys. Chem. C 2016, 120 (16), 8509-8524.

(103) Palstra, T.; Ramirez, A.; Cheong, S.-W.; Zegarski, B.; Schiffer, P.; Zaanen, J. Transport Mechanisms in Doped LaMnO3: Evidence for Polaron Formation. Phys. Rev. B 1997, 56 (9), 5104-5107.

(104) Zaanen, J.; Sawatzky, G. A.; Allen, J. W. Band Gaps and Electronic Structure of TransitionMetal Compounds. Phys. Rev. Lett. 1985, 55 (4), 418-421.

(105) Shannon, R. D.; IUCr. Revised Effective Ionic Radii and Systematic Studies of Interatomic Distances in Halides and Chalcogenides. Acta Crystallogr. Sect. A 1976, 32 (5), 751-767. 
TOC Graphic

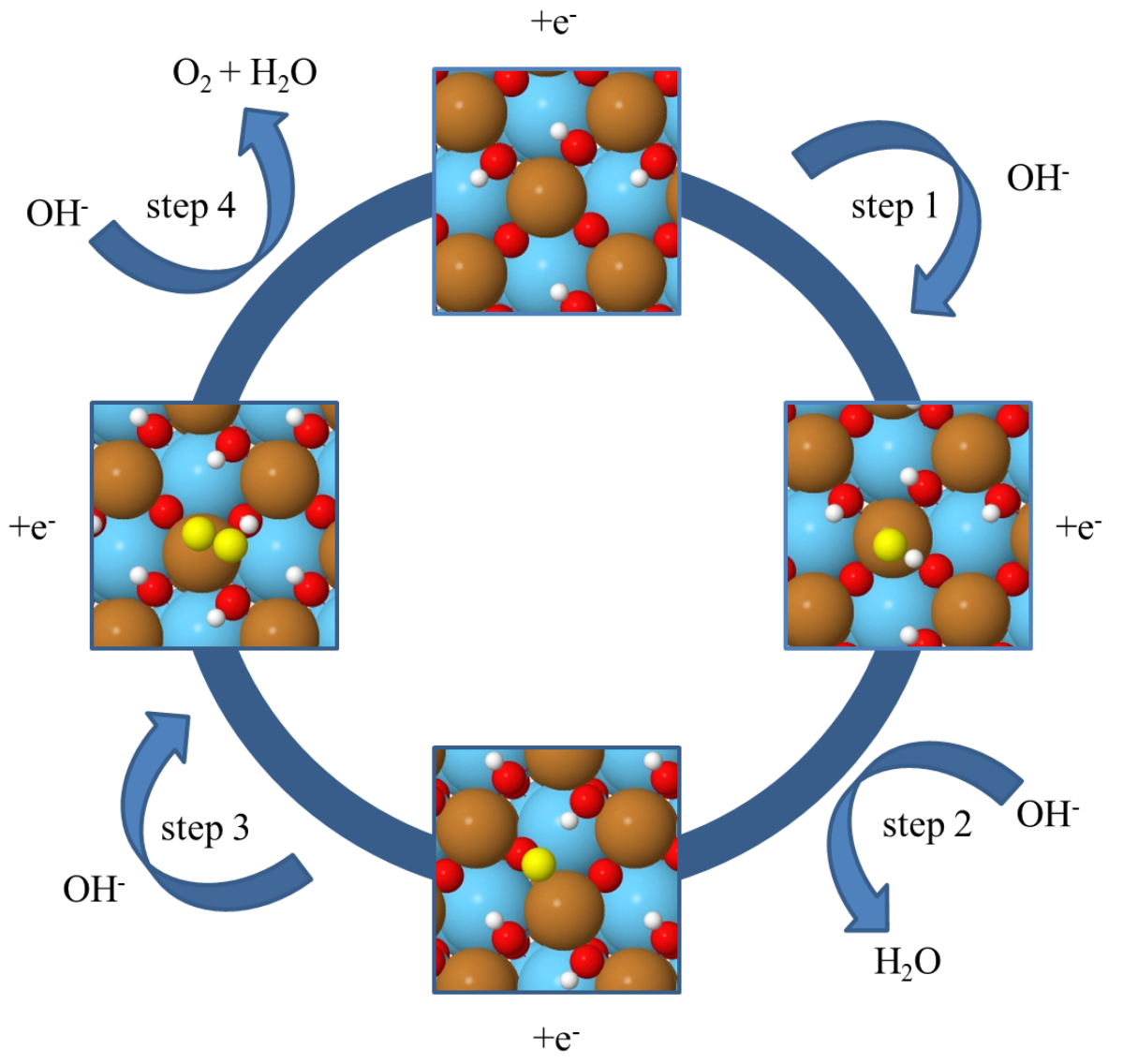

